\title{
Numerical Simulations of Tropical Squall-line Clusters:
}

\section{Two-dimensional Model}

\author{
By Masanori Yoshizaki \\ Ocean Research Institute, University of Tokyo* \\ (Manuscript received 12 November 1985, in revised form 10 March 1986)
}

\begin{abstract}
Numerical simulations of two-dimensional tropical squall-line clusters (TSL) are performed using a nonhydrostatic, anelastic cloud model in the ambient winds and stratification, which are based on the sounding in GATE on Sept. 12, 1974. Water substance in the model is divided into 6 forms; water vapor, cloud water, rain, cloud ice, graupel and hail. The parameterization of cloud microphysics is mainly based on Lin et al. (1983). The grid sizes are stretched in both horizontal and vertical directions and the model domain is $241 \mathrm{~km}$ and $14.45 \mathrm{~km}$ in the horizontal and vertical direction, respectively. A cumulonimbus is initiated by an initial thermal under an imposed low-level large-scale convergence.

Quasi-steady convection is attained after 2 hours of the model integration. The convective system is composed of convective and stratiform regions. In the convective region, a slant strong updraft is obtained and its angle from the horizontal is about 15 degrees. In the stratiform region, motions are nearly uniform in the horizontal direction and layer structures of strong horizontal winds are seen. There is weak updraft in the anvil cloud which is occupied by graupel and weak downdraft below the melting level where rain prevails. The sharp jumps of winds, temperature, water vapor mixing ratio and heat/moisture fluxes are obtained near the gust front on the surface. These features of the convective system simulated in the model are similar to those of the observed TSLs. However, fast propagation of the convective system is not well simulated. This may be due to that the simulated pressure rise on the surface is not sufficiently large to proceed the convective system fast.
\end{abstract}

\section{Introduction}

A group of cumulonimbi - cloud cluster - is frequently modulated by the passages of largescale disturbances. For example, cloud clusters were enhanced at and ahead of trough axes of synoptic-scale easterly waves and suppressed at and ahead of their ridge axes during GATE. Elucidation of this process may be one of the most important and interesting problems in tropical meteorology.

Tropical cloud clusters are roughly divided into two types; squall-line clusters (TSL) and nonsquall ones (NC) (Houze and Betts, 1981). Propagation of the TSL is often faster than the

\footnotetext{
*Present affiliation: Department of Atmospheric Sciences, University of Illinois at Urbana-Champaign, IL 61801 .
}

environmental wind at any altitude. The TSL has a distinct oval cirrus shield and an arcshaped leading edge. On the other hand, the NC does not have so distinct characteristics compared with the TSL; the NC travels more slowly than the TSL and does not possess a distinct oval shield nor an arc-shaped leading edge. The overwhelming majority of cloud clusters consisted of NCs in GATE.

Although NC and TSL have differences in motion and appearance, they exhibit surprising similarities in other aspects of their structures (Houze and Betts, 1981). Thus, Leary and Houze (1979a) considered that TSL and NC are combined structures of a basic element and named it as mesoscale precipitation feature (MPF). A TSL generally consists of a MPF. On the other hand, an NC has one or several 

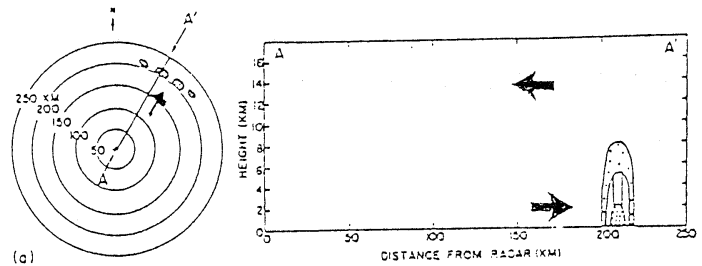

(c)
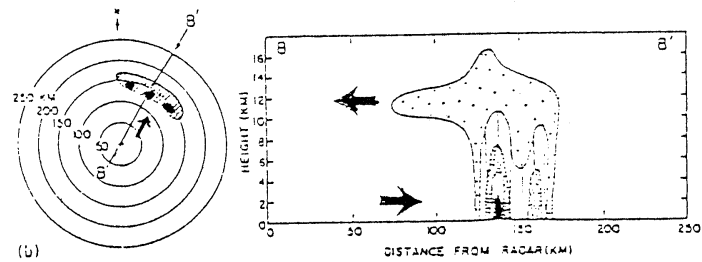

(i)
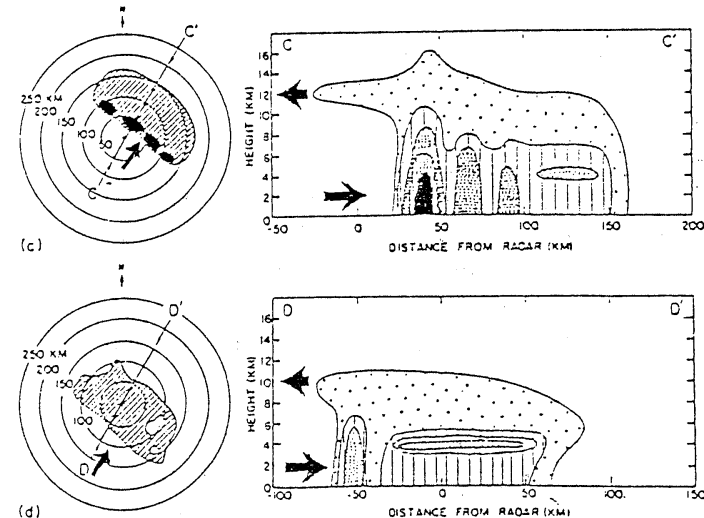

Fig. 1 Schematic of the structure of a mesoscale precipitation feature (MPF) as viewed by radar in horizontal and vertical cross sections during (a) formative, (b) intensifying, (c) mature and (d) dissipating stages of its life cycle (Leary and Houze, 1979a). The outside contour of radar reflectivity is the weakest detectable echo, and the inner contours are for successively higher reflectivity values. Heavy arrows on horizontal cross sections indicate direction of the low-level winds. Arrows on vertical cross sections indicate directions of the low-level and upper-level winds relative to the MPF.

MPFs, and therefore exhibits complex features compared with the TSL. Fig. 1 shows the horizontal and vertical structures of a MPF as viewed by radar during (a) formative, (b) intensifying, (c) mature and (d) decaying stages. It is noticed that in the mature and decaying stages, the MPF has two distinct regions; convective and stratiform regions. The convective region is the arc-shaped leading edge in which cumulonimbi develop and strong precipitation $(>10 \mathrm{~mm}$ $\mathrm{hr}^{-1}$ ) is seen. Its horizontal width is about 10 $\mathrm{km}$. On the other hand, the stratiform region is occupied by the anvil cloud at the rear of the leading edge and has weak stratiform (continuous) precipitation $\left(1-10 \mathrm{~mm} \mathrm{hr}^{-1}\right)$. Its horizontal scale is about $100 \mathrm{~km}$ and very wide compared with the convective region. Although it is very weak, the stratiform precipitation is widespread and its amount is approximately equal to that of convective precipitation (Houze, 1977). Thus, stratiform precipitation is not negligible for water budget. In the stratiform region the bright band is often found at the melting level when it is seen by radar in the vertical section. The presence of the bright band indicates that strong convective cells are absent and ice particles are gently falling downward in the anvil cloud. The similar feature as the MPF is also seen in the rainband of hurricanes (Barnes et al., 1983). Thus the MPF is the basic element of tropical cloud clusters, so that an investigation of the TSL would be useful to increase our understanding of physical processes in tropical cloud clusters.

Fig. 2 shows the vertical cross sections of relative winds in and around (a) the TSL observed in GATE on Sept. 12, 1974 (Gamache and Houze, 1982) and (b) the West African TSL observed in COPT 81 (Roux et al., 1984). Both TSLs move in the leftward direction. The convective-scale and mesoscale circulations are found in the convective and stratiform regions, respectively. In the convective region, a strong updraft is seen and slants at the angle of about 20 degrees for the case of Fig. 2(b). On the other hand, in the stratiform region, the mesoscale circulation is nearly uniform in the horizontal direction and there are layer structures of strong horizontal winds; a rightward wind at the height of $4-10 \mathrm{~km}$, a leftward wind below the anvil cloud and a rightward wind near the surface (not observed in Fig. 2(b)). It is noticed that there are weak updraft in the anvil cloud and weak downdraft below it.

LeMone et al. (1984a) showed that the slope of the cloud top in the leading edge from the horizontal is very small, between 20 and 30 degrees. This slant circulation in the convective region determines the sign of the momentum flux perpendicular to the TSL, i.e., $\overline{u^{\prime} w^{\prime}}>0$. Here $u^{\prime}$ and $w^{\prime}$ are wind deviations from the 


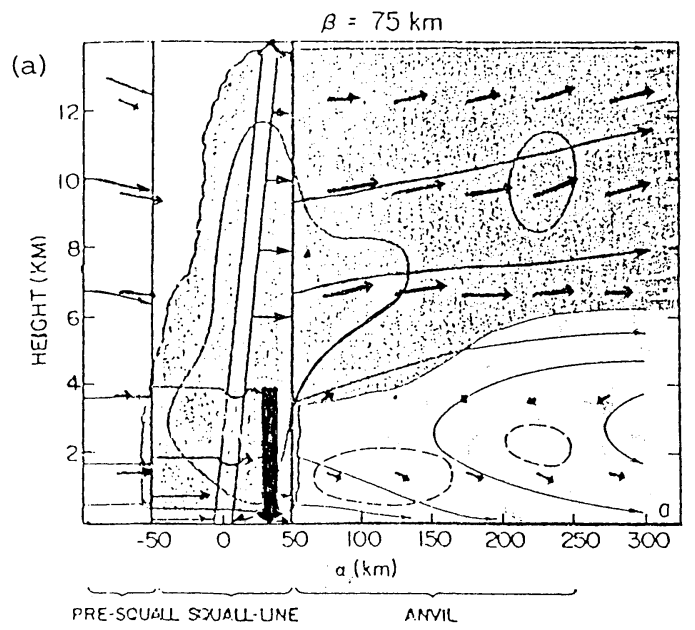

(b)

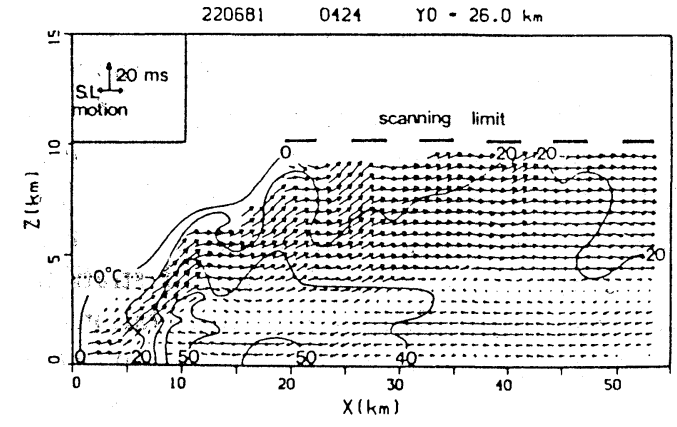

Fig. 2 (a) Vertical cross section of relative streamflow in the TSL (adopted from Fig. 16(a) in Gamache and Houze, 1982). Solid contours indicate regions where $\omega<-25 \mathrm{mb} \mathrm{h}^{-1}$ (upward motion); dashed contours indicate regions where $\omega>25 \mathrm{mb} \mathrm{h}^{-1}$ (downward motion). Heavy arrows originate at data points. Each arrow represents a 30 min displacement. The thin line enclosing the shaded region indicates the probable extent of visible cloud. (b) Vertical cross section of relative winds in the West African TSL observed in COPT 81 by dual-Doppler radar (adopted from Fig. 4(c) in Roux et al., 1984).

mean in the front-to-rear and vertical directions, respectively. Indeed, LeMone (1983) and LeMone et al. (1984b) obtained that $\overline{u^{\prime} w^{\prime}}$ is positive in the most part of the troposhere, by analyzing the data from aircraft flights in cloud lines. This means that the sign of the flux is not consistent with the mixing length theory under the jet-type basic wind. On the other hand, the momentum flux parallel to the line, $\overline{v^{\prime} w^{\prime}}$ is found to be transported downgradient, so that the mixing length theory is applicable. Since all motions in the cloud line are nearly 2-dimensional and no pressure force works in the direction parallel to the cloud lines, the momentum in the direction parallel to the cloud line can mix in the same manner as the conservative quantities.

Johnson and Nicholls (1983) got composite surface horizontal distributions of temperature, specific humidity, pressure and heat fluxes around and in the TSL observed in GATE on Sept. 12, 1974. After the TSL passed, sharp jumps of temperature, specific humidity and pressure are seen, reaching $4-5 \mathrm{~K}, 3 \times 10^{-3} \mathrm{~kg}$ $\mathrm{kg}^{-1}$ and $2 \mathrm{hPa}$, respectively. There are also large amounts of sensible and latent heat fluxes in the TSL, reaching about $100 \mathrm{~W} \mathrm{~m}^{-2}$ and $400 \mathrm{~W}$ $\mathrm{m}^{-2}$, respectively.

In this study, we try to simulate the follow- ing features of the TSL; 1) the coexistence of convective and stratiform regions, 2) the slant updraft in the convective region and the separate circulations in the stratiform region consisting of weak updraft in the anvil cloud and weak downdraft below it, 3) sharp jumps of physical quantities at the gust front on the surface and 4) fast propagation of the TSL. Also, we try to examine heat and moisture budgets in the TSL.

In order to simulate above-mentioned features of the TSL, some numerical works were made so far. Brown (1979) attempted to simulate weak uniform unsaturated downdraft in the stratiform region and showed that evaporation of rainfall can account for weak uniform subsidence below the anvil cloud. However, he used the hydrostatic unfiltered equations and parameterized cumulus convection through 1-dimensional plume model, so that the convective-scale structures were not resolved in his model. Raymond (1984) tried to simulate the tropical and midlatitude squall lines as an initial value problem of the linearized wave-CISK model incorporating time-lag effects in the updraft and downdraft. Flow structures and propagation speed are well simulated in his model. However, the flaw in his results is that his model produced two oppositely directed squall-lines, although one squall- 
line which propagates in the upwind direction occurs in the real situation. By using the warm rain model, Moncrieff and Miller (1976) and Yamasaki (1984) made numerical experiments of the TSL and got some features of the TSL. Especially, Yamasaki simulated the long-lasting TSL which has the convective and stratiform clouds. However, stratiform precipitation and mesoscale circulation in the stratiform region are not seen in his results. Recently Soong and Chen (1984) tried to simulate the tropical cloud clusters by using the cold rain model including ice-phase and got many features of the TSL.

To simulate above-mentioned features of the TSL, we make a 2-dimensional numerical model which contains both dynamical and cloud microphysical processes. The large-scale low-level convergence is closely related to the convective activity, so that we include the large-scale convergence/divergence in the model. Ice particles whose terminal velocities are very small compared with those of raindrops seem to occupy the anvil cloud in the stratiform region. Thus we include ice-phase in the cloud microphysics and divide water substance into 6 forms; water vapor, cloud water, rain, cloud ice, graupel and hail. Section 2 describes the model we develop. Section 3 presents results of our numerical experiments and compare these results with observational facts. The conclusion is presented in the last section.

\section{Model}

\section{2-1. Equations of motion}

Our model is two-dimensional in the $(x, z)$ plane, where $x$ and $z$ are horizontal and vertical axes, respectively. The $y$-axis denotes the horizontal axis normal to the $(x, z)$ plane and $\frac{\partial}{\partial y}=0$ is assumed. The equations of motion are written as

$$
\begin{aligned}
\frac{\partial u^{\prime}}{\partial t}= & -w \eta+v \zeta-\frac{\partial K}{\partial x}-C_{p} \bar{\theta}_{v} \frac{\partial \pi^{\prime}}{\partial x} \\
& +D\left(u^{\prime}\right)+F c-\left(\bar{V}-v^{*}\right) \bar{\zeta}, \\
\frac{\partial v^{\prime}}{\partial t}= & -u \zeta+w \xi+D\left(v^{\prime}\right)+\left(\bar{U}-u^{*}\right) \zeta, \\
\frac{\partial w}{\partial t}= & -v \xi+u \eta-\frac{\partial K}{\partial z}-C_{p} \bar{\theta}_{v} \frac{\partial \pi^{\prime}}{\partial z}
\end{aligned}
$$

$$
\begin{aligned}
& +D\left(w^{\prime}\right)+g\left(\frac{\theta^{\prime}}{\bar{\theta}}+0.61 Q_{V}^{\prime}\right. \\
& \left.-Q_{C}-Q_{R}-Q_{I}-Q_{G}-Q_{H}\right) .
\end{aligned}
$$

Here $u, v$ and $w$ are velocity components in the $x$-, $y$ - and $z$-directions, respectively, and $u=\bar{U}+$ $u^{\prime}-u^{*}$ and $v=\bar{V}+v^{\prime}-v^{*}$. The overbar represents the basic state which is assumed to be a function of $z$ alone. Dashed variables are the deviations from the basic state. $u^{*}$ and $v^{*}$ are velocities of the coordinate system relative to the surface and we take $u^{*}=-5.5 \mathrm{~m} \mathrm{~s}^{-1}$ and $v^{*}=0 \mathrm{~m} \mathrm{~s}^{-1}$. Vorticity components $\xi, \eta$ and $\zeta$ are defined as

$$
\begin{gathered}
\zeta=-\frac{\partial v}{\partial z}, \quad \eta=\frac{\partial u}{\partial z}-\frac{\partial w}{\partial x}, \\
\zeta=\frac{\partial v}{\partial x}+f .
\end{gathered}
$$

In the above equations, $f$ is the Coriolis parameter $\left(5 \times 10^{-5} \mathrm{~s}^{-1}\right), C_{p}$ the specific heat of air at constant pressure and $\mathrm{K}$ the kinetic energy given by $\left(u^{2}+v^{2}+w^{2}\right) / 2 . \pi, \theta$ and $\theta_{V}$ are nondimensional pressure, potential temperature and virtual potential temperature, respectively, and $\pi=\bar{\pi}+\pi^{\prime}$ and $\theta=\theta_{0}(x, y, z)+\theta^{\prime} . \theta_{0}$ is related to $\bar{U}$ and $\bar{V}$ by the geostrophic relation;

$\frac{\partial \theta_{0}}{\partial y}=-\frac{f \theta_{0}}{g} \frac{\partial \bar{U}}{\partial z}, \quad \frac{\partial \theta_{0}}{\partial x}=\frac{f \theta_{0}}{g} \frac{\partial \bar{V}}{\partial z}$.

Water is divided into 6 forms and $Q_{V}, Q_{C}, Q_{R}$, $Q_{I}, Q_{G}$ and $Q_{H}$ in the buoyant term represent mixing ratios of water vapor, cloud water, rain, cloud ice, graupel and hail, respectively. $D(A)$ represents the diffusion term of a physical quantity $A$ and will be discussed in subsection 2-3. $F_{C}$ is the forcing term representing an imposed large-scale convergence/divergence and will be discussed in subsection 2-7.

The continuity equation is given as

$$
\frac{\partial}{\partial x}\left(\bar{\rho} u^{\prime}\right)+\frac{\partial}{\partial z}(\bar{\rho} w)=O,
$$

where $\bar{\rho}$ is the density in the basic state.

The nondimensional pressure is determined from (1), (3) and (6) by solving the following equation; 
$\frac{\partial}{\partial x}\left(C_{p} \bar{\theta}_{v} \bar{\rho} \frac{\partial \pi^{\prime}}{\partial x}\right)+\frac{\partial}{\partial z}\left(C_{p} \bar{\theta}_{v} \bar{\rho} \frac{\partial \pi^{\prime}}{\partial z}\right)=\sigma$.

Here $\sigma$ is defined by

$\frac{\partial}{\partial x}\left\{\bar{\rho}[\right.$ RHS of (1)] $\}+\frac{\partial}{\partial z}\{\bar{\rho}$ [RHS of (3)] $\}$,

where RHS denotes the right-hand side omitting the pressure term.

\section{2-2. Equations of water and potential tempe- rature}

As mentioned above, water is divided into 6 forms in the model; water vapor, cloud water, rain, cloud ice, graupel ${ }^{*)}$ and hail. The shapes of liquid and ice are assumed to be spherical. Size distributions of rain, graupel and hail are assumed to be inversely exponential with respect to diameters. Cloud ice has a single size whose diameter is assumed to be $2 \times 10^{-5} \mathrm{~m}$. Its density is $9.17 \times 10^{2} \mathrm{~kg} \mathrm{~m}^{-3}$. In our model only rain, graupel and hail fall down with terminal velocities.

Table 1 shows parameters of rain, graupel and hail. The coefficients $n_{0 R}$ and $n_{0 H}$ are given by Marshall and Palmer (1948) as $8 \times 10^{6} \mathrm{~m}^{-4}$ and by Federer and Waldvogel (1975) as $4 \times 10^{4}$ $\mathrm{m}^{-4}$, respectively. On the other hand, it is difficult to give the value of $n_{0 G}$ in the TSL, since there are few observations of ice in tropics. Leary and Houze (1979b) estimated existence of hexagonal graupel in the anvil cloud, with the assumption that ice particles, when melted, would produce the size distribution of raindrop corresponding to those obtained from the research ships in GATE. Here, in order to get $n_{0 G}$, we assume that graupel in our model is hexagonal graupel and

Table 1 Parameters of rain, graupel and hail

\begin{tabular}{|c|c|c|c|}
\hline & Rain & Graupel & Hail \\
\hline Mixing ratio $\left(\mathrm{kg} \cdot \mathrm{kg}^{-1}\right)$ & $Q_{R}$ & $Q_{G}$ & $Q_{H}$ \\
\hline $\begin{array}{l}\text { Size distribution } \\
\qquad n\left(m^{-4}\right)\end{array}$ & $\begin{array}{l}n_{R}= \\
n_{0 R} e^{-\lambda_{R} D_{R}}\end{array}$ & $\begin{array}{l}n_{G}= \\
n_{0 G} e^{-\lambda_{R} D_{R}}\end{array}$ & $\begin{array}{l}n_{H}= \\
n_{0 H} e^{-\lambda}{ }_{H} D_{H}\end{array}$ \\
\hline$n_{0}\left(m^{-4}\right)$ & $8 \times 10^{6}$ & $7.65 \times 10^{6}$ & $4 \times 10^{4}$ \\
\hline$\lambda$ & $\begin{array}{l}\lambda_{R}= \\
\left(\frac{\pi \rho_{W} n_{0 R}}{\bar{\rho} Q_{R}}\right)^{1 / 4}\end{array}$ & $\begin{array}{l}\lambda_{G}= \\
\left(\frac{\pi \rho_{G} n_{0 G}}{\bar{\rho} Q_{G}}\right)^{1 / 4}\end{array}$ & $\begin{array}{l}\lambda_{H}= \\
\left(\frac{\pi \rho_{H} n_{0 H}}{\bar{\rho} Q_{H}}\right)^{1 / 4}\end{array}$ \\
\hline$\rho\left(k g \cdot m^{-3}\right)$ & $\rho_{W}=10^{3}$ & $\rho_{G}=0.84 \times 10^{2}$ & $\rho_{H}=0.9 \times 10^{3}$ \\
\hline $\begin{array}{l}\text { Fall speed } \\
\quad U_{D} \\
\text { D: Diameter }\end{array}$ & $\begin{array}{l}U_{D R}= \\
a D_{R}^{b}\left(\frac{\rho_{0}}{\bar{\rho}}\right)^{1 / 2} \\
a=842.0 \\
b=0.8\end{array}$ & $\begin{array}{l}U_{D G}= \\
c D_{G}^{d}\left(\frac{\rho_{0}}{\vec{\rho}}\right)^{1 / 2} \\
c=56.4 \\
d=0.57\end{array}$ & $\begin{array}{c}U_{D H}= \\
\left(\frac{4 g \rho_{H}}{3 C_{D} \bar{\rho}}\right)^{1 / 2} D_{H}^{1 / 2} \\
C_{D}: \text { drag coefficient } \\
0.6\end{array}$ \\
\hline $\begin{array}{l}U= \\
\frac{\int_{0}^{\infty} U_{D} n(D) D^{3} d D}{\int_{0}^{\infty} n(D) D^{3} d D}\end{array}$ & $\begin{array}{l}U_{R}= \\
\frac{a \Gamma(b+4)}{6 \lambda_{R}^{b}}\left(\frac{\rho_{0}}{\bar{\rho}}\right)^{1 / 2}\end{array}$ & $\begin{array}{l}U_{G}= \\
\frac{c \Gamma(d+4)}{6 \lambda_{G}^{d}}\left(\frac{\rho_{0}}{\bar{\rho}}\right)^{1 / 2}\end{array}$ & $\begin{array}{l}U_{H}= \\
\frac{\Gamma(4.5)}{6 \lambda_{H}^{1 / 2}}\left(\frac{4 g \rho_{H}}{3 c_{D} \bar{\rho}}\right)^{1 / 2}\end{array}$ \\
\hline
\end{tabular}

*)The term "graupel" is used rather loosely to represent ice particles which fall slowly in the anvil cloud. 


$$
\int_{0}^{\infty} n_{G}\left(D_{G}\right) U_{G} d G_{G}=\int_{0}^{\infty} n_{R}\left(D_{R}\right) U_{R} d D_{R}
$$

Here $U_{G}=c D_{G}{ }^{d}$ and $M_{G}=e D_{G}{ }^{3}$ are given where $U_{G}, D_{G}$ and $M_{G}$ are the terminal velocity of graupel in $\mathrm{m} \mathrm{s}^{-1}$, the diameter in $\mathrm{m}$ and the mass in $\mathrm{kg}$, respectively. The coefficients, $c, d$ and $e$ are given as $c=56.4, d=0.57$ and $e=44$, which are the values of hexagonal graupel obtained by Locatelli and Hobbs (1974) in a laboratory experiment. The density of graupel is $84 \mathrm{~kg} \mathrm{~m}^{-3}$. Assuming $\bar{\rho}=0.6 \mathrm{~kg} \mathrm{~m}^{-3}$ and $Q_{G}=Q_{R}=1 \times 10^{-3} \mathrm{~kg} \mathrm{~kg}^{-1}$, we determine the value of $n_{0 G}$ as $7.65 \times 10^{6} \mathrm{~m}^{-4}$. Note that graupel in our model has low density and large number density.

The parameterization of the cloud microphysics is mainly based on Lin et al. (1983). Main differences of our cloud parameterization from their model are given as follows: (1) The term "graupel" is adopted instead of snow, although their terminal velocities are similar. However, the number of graupel is very large and thus its accretion rates are very large compared with snow in Lin et al.'s model. (2) The

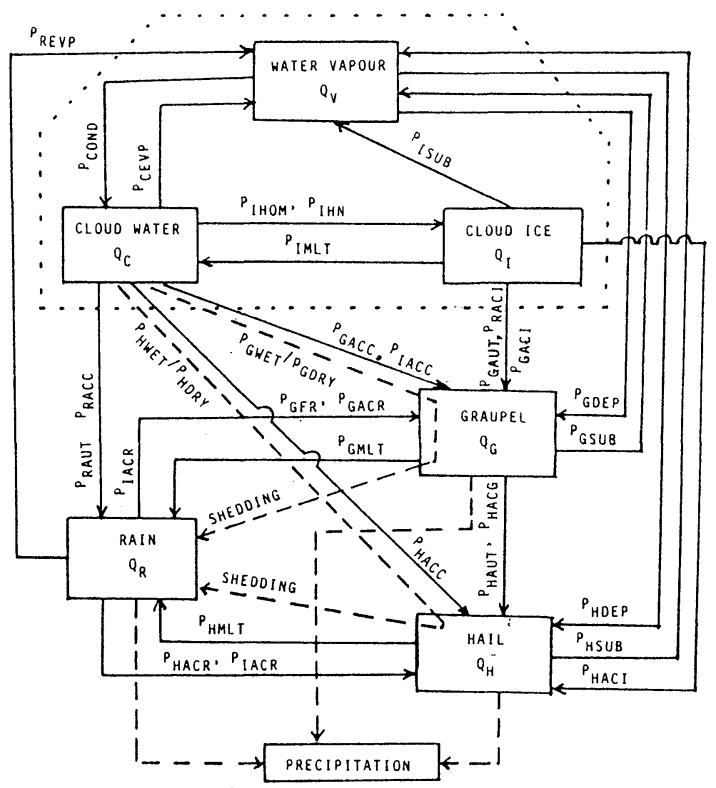

Fig. 3 Microphysical processes among water substances. The productions among $Q_{V}, Q_{C}$ and $Q_{I}$ enclosed by the dotted line occurs instantaneously. Details about production rates are given in Appendix. wet growth of graupel is included, since all liquids collected by the dry growth of graupel cannot be sometimes frozen completely. (3) Transfer of cloud water to graupel in the Bergeron process is not included in our model, because it can be expressed by the combination of evaporation of cloud water and deposition of water vapor on graupel. (4) The non-precipitating substances such as water vapor, cloud water and cloud ice are treated independently. The microphysical processes used in this model are illustrated in Fig. 3 and explained in detail in Appendix. The mass-weighted mean terminal velocities of rain, graupel and hail are shown in Fig. 4. Note that the terminal velocity of graupel is much smaller than those of rain and hail.

The equations of water and potential temperature are written for two different temperature regimes.

(i) When the temperature is below $0^{\circ} \mathrm{C}\left(T<T_{0}\right.$ $=273.16 \mathrm{~K}$ ),

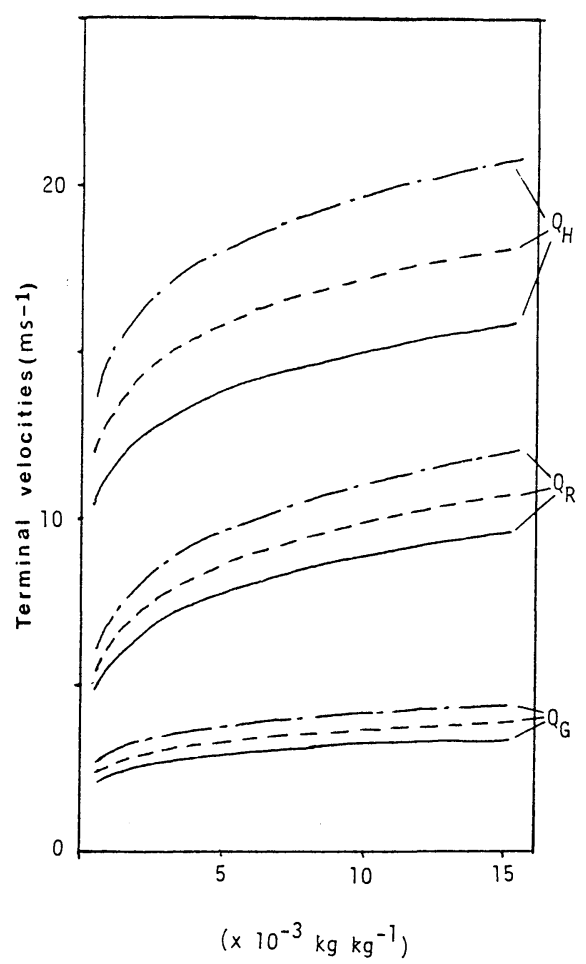

Fig. 4 Terminal velocities $\left(\mathrm{m} \mathrm{s}^{-1}\right.$ ) of rain, graupel and hail. The solid, dashed and dotted-dashed lines denote terminal velocities at the levels where the air densities are 1.013, 0.701 and $0.492 \mathrm{~kg} \mathrm{~m}^{-3}$, respectively. 


$$
\begin{aligned}
\frac{\partial Q_{V}^{\prime}}{\partial t}= & A d v\left(Q_{V}\right)+D\left(Q_{V}^{\prime}\right)+P_{C E V P}+P_{I S U B} \\
& +P_{R E V P}\left(\delta_{1}\right)-P_{C O N D}+P_{G S U B} \\
& -P_{G D E P}+P_{H S U B}-P_{H D E P}
\end{aligned}
$$

$\frac{\partial Q_{C}}{\partial C}=A d v\left(Q_{C}\right)+D\left(Q_{C}\right)-P_{I H O M}\left(\delta_{2}\right)$

$-P_{I H N}\left(1-\delta_{2}\right)+P_{C O N D}-P_{C E V P}$

$-P_{R A U T}-P_{R A C C}-P_{G A C C}-P_{H A C C}$

$-P_{I A C C}$,

$$
\begin{aligned}
& \frac{\partial Q_{I}}{\partial t}=A d v\left(Q_{I}\right)+D\left(Q_{I}\right)+P_{I H O M}\left(\delta_{2}\right) \\
& \quad+P_{I H N}\left(1-\delta_{2}\right)-P_{R A C I}-P_{I S U B}-P_{G A U T} \\
& \quad-P_{G A C I}\left(\text { or } P_{G A C I}^{\prime}\right)-P_{H A C I}\left(\text { or } P_{H A C I}^{\prime}\right),
\end{aligned}
$$

$$
\begin{aligned}
\frac{\partial Q_{R}}{\partial t} & =A d v\left(Q_{R}\right)+D\left(Q_{R}\right)+\frac{1}{\bar{\rho}} \frac{\partial}{\partial z}\left(\bar{\rho} U_{R} Q_{R}\right) \\
& +P_{R A U T}+P_{R A C C}-P_{I A C R}-P_{G F R} \\
& -P_{R E V P}\left(\delta_{1}\right)-P_{G A C R}\left(\text { or } P_{G A C R}^{\prime}\right) \\
& -P_{H A C R}\left(\text { or } P_{H A C R}^{\prime}\right),
\end{aligned}
$$

$$
\begin{aligned}
\frac{\partial Q_{G}}{\partial t} & =A d v\left(Q_{G}\right)+D\left(Q_{G}\right)+\frac{1}{\bar{\rho}} \frac{\partial}{\partial z}\left(\bar{\rho} U_{G} Q_{G}\right) \\
& -P_{G S U B}+P_{G D E P}+P_{G A U T}-P_{H A U T} \\
& +P_{G F R}+P_{R A C I}+P_{I A C C}+P_{I A C R}\left(\delta_{3}\right) \\
& +P_{G D R Y}\left(\text { or } P_{G W E T}\right),
\end{aligned}
$$

$$
\begin{aligned}
\frac{\partial Q_{H}}{\partial t} & =A d v\left(Q_{H}\right)+D\left(Q_{H}\right)+\frac{1}{\bar{\rho}} \frac{\partial}{\partial z}\left(\bar{\rho} U_{H} Q_{H}\right) \\
& +P_{H A U T}+P_{H D E P}-P_{H S U B} \\
& +P_{I A C R}\left(1-\delta_{3}\right)+P_{H D R Y}\left(\text { or } P_{H W E T}\right),
\end{aligned}
$$

$$
\begin{aligned}
\frac{\partial \theta^{\prime}}{\partial t} & =A d v(\theta)+D\left(\theta^{\prime}\right)-v^{\prime} \frac{\partial \theta_{0}}{\partial y} \\
& +\frac{L_{f}}{C_{p \bar{\pi}}}\left[P_{G A C C}+P_{I A C C}+P_{H A C C}+P_{I A C R}\right. \\
& +P_{G F R}+P_{H A C R}\left(\text { or } P_{H A C R}^{\prime}\right)+P_{G A C R} \\
& \left.\left(\text { or } P_{G A C R}^{\prime}\right)+P_{I H O M}\left(\delta_{2}\right)+P_{I H N}\left(1-\delta_{2}\right)\right] \\
& +\frac{L_{v}}{C_{p \bar{\pi}}}\left[P_{C O N D}-P_{C E V P}-P_{R E V P}\left(\delta_{1}\right)\right]
\end{aligned}
$$

$$
\begin{aligned}
& +\frac{L_{s}}{C_{p \bar{\pi}}}\left[P_{G D E P}+P_{H D E P}-P_{G S U B}\right. \\
& \left.-P_{H S U B}-P_{I S U B}\right] .
\end{aligned}
$$

(ii) When the temperature is above $0^{\circ} \mathrm{C}(T>$ $T_{0}$ ),

$$
\begin{aligned}
\frac{\partial Q_{V}^{\prime}}{\partial t}= & A d v\left(Q_{V}\right)+D\left(Q_{V}^{\prime}\right) \\
& +P_{C E V P}+P_{R E V P}\left(\delta_{1}\right)-P_{C O N D},
\end{aligned}
$$

$\frac{\partial Q_{c}}{\partial t}=A d v\left(Q_{C}\right)+D\left(Q_{C}\right)+P_{C O N D}-P_{C E V P}$

$-P_{R A U T}-P_{R A C C}+P_{I M L T}$,

$\frac{\partial Q_{I}}{\partial t}=\operatorname{Adv}\left(Q_{I}\right)+D\left(Q_{I}\right)-P_{I M L T}$,

$$
\begin{aligned}
\frac{\partial Q_{R}}{\partial t}= & A d v\left(Q_{R}\right)+D\left(Q_{R}\right)+\frac{1}{\bar{\rho}} \frac{\partial}{\partial z}\left(\bar{\rho} U_{R} Q_{R}\right) \\
& +P_{R A U T}+P_{R A C C}-P_{R E V P}\left(\delta_{1}\right) \\
& +P_{G M L T}+P_{H M L T}, \\
\frac{\partial Q_{G}}{\partial t}= & A d v\left(Q_{G}\right)+D\left(Q_{G}\right)+\frac{1}{\bar{\rho}} \frac{\partial}{\partial z}\left(\bar{\rho} U_{G} Q_{G}\right) \\
& -P_{G M L T}-P_{H A C G},
\end{aligned}
$$

$\frac{\partial Q_{H}}{\partial t}=A d v\left(Q_{H}\right)+D\left(Q_{H}\right)+\frac{1}{\bar{\rho}} \frac{\partial}{\partial z}\left(\bar{\rho} U_{H} Q_{H}\right)$

$$
-P_{H M L T}+P_{H A C G},
$$

$$
\begin{aligned}
\frac{\partial \theta^{\prime}}{\partial t}= & A d v(\theta)+D\left(\theta^{\prime}\right)-v^{\prime} \frac{\partial \theta_{0}}{\partial y} \\
& +\frac{L_{v}}{C_{p} \bar{\pi}}\left[P_{C O N D}-P_{C E V P}-P_{R E V P}\left(\delta_{1}\right)\right] \\
& -\left[\frac{L_{f}}{C_{p} \bar{\pi}}+\frac{C_{w}\left(T-T_{0}\right)}{C_{p} \bar{\pi}}\right]\left(P_{G M L T}\right. \\
& \left.+P_{H M L T}\right)-\frac{L_{f}}{C_{p} \bar{\pi}} P_{I M L T} .
\end{aligned}
$$

Here $L_{f}, L_{v}$ and $L_{s}$ are latent heats of fusion, vaporization and sublimation, respectively. $C_{w}$ is the specific heat of water, $\delta_{1}, \delta_{2}$ and $\delta_{3}$ are defined as

$$
\begin{aligned}
& \delta_{1}=\left\{\begin{array}{l}
1, \text { for } Q_{I}+Q_{C}=0 \text { and } S=Q_{V} / Q_{V S} \\
\quad \begin{array}{l}
< \\
0,
\end{array}
\end{array}\right. \\
& \delta_{2}=\left\{\begin{array}{l}
1, \text { for } T<T_{1}=238.16 \mathrm{~K}\left(-35^{\circ} \mathrm{C}\right) \\
0, \text { otherwise }
\end{array}\right. \\
& \delta_{3}=\left\{\begin{array}{l}
1, \text { for } Q_{R}<0.5 \times 10^{-3} \mathrm{~kg} \mathrm{~kg}^{-1} \\
0, \text { otherwise. }
\end{array}\right.
\end{aligned}
$$


$\operatorname{Adv}(A)$ is the advection term of $A$ and is defined by

$$
-\frac{1}{\bar{\rho}}\left[\frac{\partial}{\partial x}(\bar{\rho} u A)+\frac{\partial}{\partial z}(\bar{\rho} w A)\right] .
$$

The third terms of the right hand side in (15) and (22) denote the northward advection of heat where $\frac{\partial \theta_{0}}{\partial y}$ is assumed to be a function of $z$ alone.

\section{2-3. Subgrid turbulence parameterization and damping of computational noises}

$D$ in (1), (2) and (3) is composed of three terms; the mixing term $D_{S}$ due to subgrid turbulence, the nonlinear damping term $D_{N}$ and the Rayleigh friction term $D_{R}$.

$D_{S}$ is calculated by using the parameterization of Klemp and Wilhelmson (1978), in which the subgrid-scale kinetic energy $E=\overline{\left(u^{1 / 2}\right.}+\overline{v^{\prime \prime 2}}+$ $\left.\overline{w^{\prime \prime 2}}\right) / 2$ is predicted. Here double primes and double overbars denote subgrid-scale and gridaveraged quantities, respectively. The subgrid diffusion term for the momentum in the $x$ direction is given, as an example, by

$D_{S}(u)=-\frac{\partial}{\partial x}\left(\overline{\overline{u^{\prime \prime 2}}}\right)-\frac{\partial}{\partial z}\left(\overline{\overline{u^{\prime \prime} w^{\prime \prime}}}\right)$,

where

$$
\overline{\overline{u^{\prime 2}}}=-2 K_{m} \frac{\partial u}{\partial x}+\frac{2}{3} E
$$

and

$$
\overline{\overline{u^{\prime \prime} w^{\prime \prime}}}=-K_{m}\left(\frac{\partial w}{\partial x}+\frac{\partial u}{\partial z}\right) .
$$

Here $K_{m}$ is the momentum eddy mixing coefficient. By assuming $K_{m}=C \Delta E^{1 / 2}$, the prognostic equation for $K_{m}$ is given as

$$
\begin{aligned}
\frac{\partial K_{m}}{\partial t} & =A d v\left(K_{m}\right)+\frac{C^{2} \Delta^{2}}{2 K_{m}}(B+S) \\
& +\frac{1}{2}\left[\frac{\partial^{2}}{\partial x^{2}}\left(K_{m}{ }^{2}\right)+\frac{\partial^{2}}{\partial z^{2}}\left(K_{m}{ }^{2}\right)\right]-\frac{K_{m}{ }^{2}}{2 \Delta^{2}},
\end{aligned}
$$

where $B$ and $S$ are the buoyant and shear terms and their treatment is similar to Klemp and Wilhelmson (1978). The coefficient $C$ is assumed to be 0.2 . Here, for simplicity, a constant length $\Delta$ of $500 \mathrm{~m}$ is taken, aslthough the horizontal and vertical grid sizes are stretched. The values of $K_{m}$ are assumed to be restricted between 1 and $600 \mathrm{~m}^{2} \mathrm{~s}^{-1}$ for computational stability.

$D_{N}$ is applied to damp computational noises (Nakamura, 1978). This damping works strongly only when amplitudes of computational noises exceed some critical values. The finite-difference form of $D_{N}$ is given in subsection 2-4.

$D_{R}$ is applied only near the lateral and top boundaries in order to avoid the reflection of internal gravity waves. $D_{R}$ is defined by $D_{R}(A)$ $=-r\left(A-A_{\text {lateral }}\right)$ where $r$ is the inverse value of the decaying time and given as $3 \times 10^{-3} \mathrm{~s}^{-1}$. Here $A$ represents $u^{\prime}, v^{\prime}, w^{\prime}, \theta^{\prime}$ and $Q_{V}{ }^{\prime}$ and $A_{\text {lateral }}$ is the value at the lateral boundary.

$D$ in (9)-(22) is composed of four terms; $D_{S}, D_{N}, D_{R}$ and the linear term $D_{L}$. For example, $D_{S}$ in (15) is given by

$$
D_{s}\left(\theta^{\prime}\right)=\frac{\partial}{\partial x}\left(K_{h} \frac{\partial \theta}{\partial x}\right)+\frac{\partial}{\partial z}\left(K_{h} \frac{\partial \theta}{\partial z}\right) .
$$

Here $K_{h}$ is given by $\operatorname{Pr}^{-1} K_{m}$ where $\operatorname{Pr}$ is the eddy Prandtl number and assumed to be 0.4. $D_{L}$ is applied in order to damp computational noises as well as $D_{N}$. The finite-difference form of $D_{L}$, which will be given in subsection $2-4$, is assumed to be the fourth-order differential form, so that the damping works strongly to suppress only short waves.

\section{2-4. Grid and finite-difference forms}

The grid points of $v$, pressure, potential temperature, water substances and the spatial weight functions $\left(h_{x}\right.$ and $\left.h_{z}\right)$ are located at the same points, while those of $u$ and $w$ are located to be staggered.

When the spatial weight functions $h_{x}$ and $h_{z}$ are assumed to be functions of $i$ and $k$, respectively, where $i$ and $k$ denote grid numbers in the $x$ - and $z$-directions, the grid sizes of the model are stretched (Yoshizaki, 1985). The first grid number of $i$ and $k$ of $h_{x}$ and $h_{z}$ is $1 / 2$. The grid number $\left(N_{x} \times N_{z}\right)$ is 280 $X$ 32. The function $h_{x}(i)$ is assumed to be symmetric with respect to the middle point $(x=0)$ of the model domain and defined as $h_{x}=16,16,14,12,10,9,8,7,6,5,4,3,2.5$, 2, 1.5, $1\left(\mathrm{i}=15 \frac{1}{2}-1391 / 2\right)$. The function $h_{z}(k)$ is stretched gradually with increasing $k$ as $h_{z}$ $=0.2,0.2,0.4,0.5,0.6,0.7,0.8,0.9,1\left(8 \frac{1}{2} \leqq\right.$ 
$k \leqq 291 / 2$ ), 1.2 and 1.4 , to be finely resolved in the lower layer. As mentioned above, the basic grid size $\Delta$ is $500 \mathrm{~m}$. Then the horizontal length of the model domain, $L$, is $241 \mathrm{~km}$ and the vertical height, $H, 14.45 \mathrm{~km}$.

The three-dimensional advection scheme of the momentum developed by Yoshizaki (1985) is applied. Under the conditions that there is no forcing/dissipation and the lateral boundary conditions are either closed or cyclic, this scheme conserves some properties; total kinetic energy is conserved and in 2-dimensional motions total enstrophy is conserved. These characteristics hold valid even in a model with stretched grid sizes. The advection scheme for heat and water is written in the flux form. This scheme conserves total heat and water, as well as their squared quantities when there is no source/sink. The fluxes of rain, graupel and hail due to their terminal velocities are calculated by applying the upstream scheme. The Poisson equation (7) is solved directly, using the method discussed in Yoshizaki (1985).

For the time integration, we apply the leap frog scheme and also the forward time scheme every 10 time steps. It is necessary to choose small time increment $\Delta t$ in order to satisfy the computational stability criterion, when the vertical grid size is very small and the terminal velocities of the precipitating particles are very large. To get large $\Delta t, Q_{C}, Q_{R}, Q_{I}, Q_{G}$ and $Q_{H}$ at the lowest grid level $(k=1 / 2)$ are assumed to be same as the values at $k=1 \frac{1}{2}$ and terminal velocity flux terms of $Q_{R}, Q_{G}$ and $Q_{H}$ at $k=1 \frac{1 / 2}{1}$ are calculated as a difference between the flux at $k=2 \frac{1 / 2}{2}$ and that at $k=-1 / 2$. On the other hand, $u, v, \theta, Q_{V}$ and $K_{m}$ at $k=1 / 2$ are calculated by using their prognostic equations. The time increment $\Delta t$ is 5 seconds in our model.

The finite-difference forms of $D_{N}$ in (1), and $D_{N}$ and $D_{L}$ in (15) are given by

$$
D_{N}\left(u^{\prime}\right)=\frac{1}{8 m \Delta t \delta u}\left\{\delta_{x}(|G| G)+\delta_{z}(|I| I)\right\},
$$

$$
D_{N}\left(\theta^{\prime}\right)=\frac{1}{8 m \Delta t \delta \theta}\left\{\delta_{x}(|J| J)+\delta_{z}(|M| M)\right\} \text {, }
$$

$$
D_{L}\left(\theta^{\prime}\right)=-\frac{1}{16 m \Delta t}\left\{\delta_{4 x}\left(\theta^{\prime}\right)+\delta_{4 z}\left(\theta^{\prime}\right)\right\},
$$

where

$$
G=\frac{\delta_{x}\left(2 u^{\prime}\right)}{h_{x}}, I=\frac{\delta_{z} u^{\prime}}{\overline{h_{z}^{2}}}+\frac{\delta_{x} w}{\bar{h}_{x}^{x}}, J=\frac{\delta_{x} \theta^{\prime}}{\bar{h}_{x}^{x}}
$$

and $M=\frac{\delta_{z} \theta^{\prime}}{\bar{h}_{z}^{2}}$.

Here finite-difference operators are defined by

$$
\begin{aligned}
\left(\delta_{x} A\right)_{i}= & A_{i+1 / 2}-A_{i-1 / 2}, \\
\left(\bar{A}^{x}\right)_{i}= & \frac{1}{2}\left(A_{i+1}+A_{i-1}\right), \\
\left(\delta_{4 x} A\right)_{i}= & \left(\frac{\delta_{x} A}{\bar{h}_{x}^{x}}\right)_{i+3 / 2}-3\left(\frac{\delta_{x} A}{\bar{h}_{x}^{x}}\right)_{i+1 / 2} \\
& +3\left(\frac{\delta_{x} A}{\bar{h}_{x}^{x}}\right)_{i-1 / 2}-\left(\frac{\delta_{x} A}{\bar{h}_{x}^{x}}\right)_{i-3 / 2} .
\end{aligned}
$$

$D_{N}$ in (27) damps 2-grid waves with an amplitude $\delta \theta$ in $m \Delta t$ time interval. When its amplitude is smaller than this value, $D_{N}$ has little effects. On the other hand, when its amplitude becomes larger, $D_{N}$ works effectively to prevent the computational overflow from occurring. The values $\delta u, \delta v$ and $\delta w$ are assigned to be $3 \mathrm{~m}$ $\mathrm{s}^{-1}$ and $\delta \theta$ is $1 \mathrm{~K} . \delta Q_{V}, \delta Q_{C}, \delta Q_{R}, \delta Q_{G}$ and $\delta Q_{H}$ are assumed to be $10^{-3} \mathrm{~kg} \mathrm{~kg}^{-1}$, while $\delta Q_{I}$ is $0.5 \times 10^{-3} \mathrm{~kg} \mathrm{~kg}^{-1}$. Likewise, $D_{L}$ in (28) suppresses 2-grid waves in $m \Delta t$ time interval. Since the difference form is the fourth-order differential form, long waves are little affected by $D_{L}$. The value of $m$ is assumed to be 50 in our model.

\section{2-5. Boundary conditions}

At the top boundary, the vertical velocity $w$ and the vertical gradients of other variables are assumed to vanish, i.e.,

$$
\begin{gathered}
w^{\prime}=\frac{\partial}{\partial z}\left(u^{\prime}, v^{\prime}, \theta^{\prime}, Q_{V}^{\prime}, Q_{C}, Q_{R}, Q_{I}, Q_{G}, Q_{H},\right. \\
\left.K_{m}, \overline{\overline{u^{\prime \prime} w^{\prime \prime}}}, \overline{\overline{v^{\prime \prime} w^{\prime \prime}}}, \overline{\overline{\theta^{\prime \prime} w^{\prime \prime}}}, \overline{\overline{Q_{V}^{\prime \prime} w^{\prime \prime}}}\right)=0 .
\end{gathered}
$$

At the bottom boundary, all velocities and the vertical gradients of $\theta$, water and $K_{m}$ are assumed to vanish, i.e., 


$$
\begin{gathered}
\tilde{u}=\tilde{v}=w=\frac{\partial}{\partial z}\left(\theta^{\prime}, Q_{V}^{\prime}, Q_{c}, Q_{R}, Q_{I}, Q_{G}, Q_{H},\right. \\
\left.K_{m}\right)=0 .
\end{gathered}
$$

Here $\tilde{u}(\tilde{v})$ is the $x$ - $(y$-) component wind relative to the surface. The subgrid momentum, heat and moisture fluxes at the surface are given as

$$
\begin{aligned}
& \overline{\overline{u^{\prime \prime} w^{\prime \prime}}}=-u_{*}^{2} \frac{\tilde{u}_{1 / 2}}{\left|\tilde{V}_{1 / 2}\right|}, \quad \overline{\overline{v^{\prime \prime} w^{\prime \prime}}}=u_{*}^{2} \frac{\widetilde{v}_{1 / 2}}{\left|\tilde{V}_{1 / 2}\right|} \\
& \overline{\overline{\theta^{\prime \prime} w^{\prime \prime}}}=-u_{*} \theta^{*}, \overline{\overline{Q_{V}^{\prime \prime} w^{\prime \prime}}}=-u_{*} Q_{V *} .
\end{aligned}
$$

Here $\tilde{u}_{1 / 2}, \tilde{v}_{1 / 2}$ and $\left|\tilde{\boldsymbol{V}}_{1 / 2}\right|$ are $\tilde{u}, \tilde{v}$ and total velocity at the lowest grid level, respectively. The scale quantities such as $u_{*}, \theta_{*}$ and $Q_{v *}$ are calculated following Barker and Baxter (1975) whose formulation is based on the MoninObukhov similarity theory and the observational analysis of Businger et al. (1971).

For the lateral boundaries, we use closed and slip conditions except the basic and large-scale convergent/divergent flows. The horizontal gra- dients of $Q_{C}, Q_{R}, Q_{I}, Q_{G}$ and $Q_{H}$ are assumed to vanish, while $\theta^{\prime}$ and $Q_{\nu}{ }^{\prime}$ are fixed to be constant.

\section{2-6. Basic state and initial condition}

Fig. 5 shows the vertical profiles of (a) temperature $\bar{T}$ and (b) $\bar{Q}_{V}$ and saturated mixing ratio of water vapor $\bar{Q}_{V S}$. The data of the research vessel Oceanographer at 09 GMT and 12 GMT on Sept. 12, 1974 in GATE are denoted by dotted and dashed lines, respectively. Basic states of $\bar{T}$ and $\bar{Q}_{V}$ used in our model are represented by the solid lines. Surface air temperature is $299 \mathrm{~K}$ and sea surface temperature is fixed to be $301 \mathrm{~K}$. Note that the melting level is located at about $4.2 \mathrm{~km}$.

Fig. 6 (a) and (b) show the vertical profiles of winds $\bar{U}$ and $\bar{V}$, respectively. The data of the research vessel Oceanographer at 09 GMT and 12 GMT are also included by dotted and dashed lines, where the directions $\bar{U}$ and $\bar{V}$ are defined to be parallel and normal to the propagation direction of the observed TSL. Note that there (a)

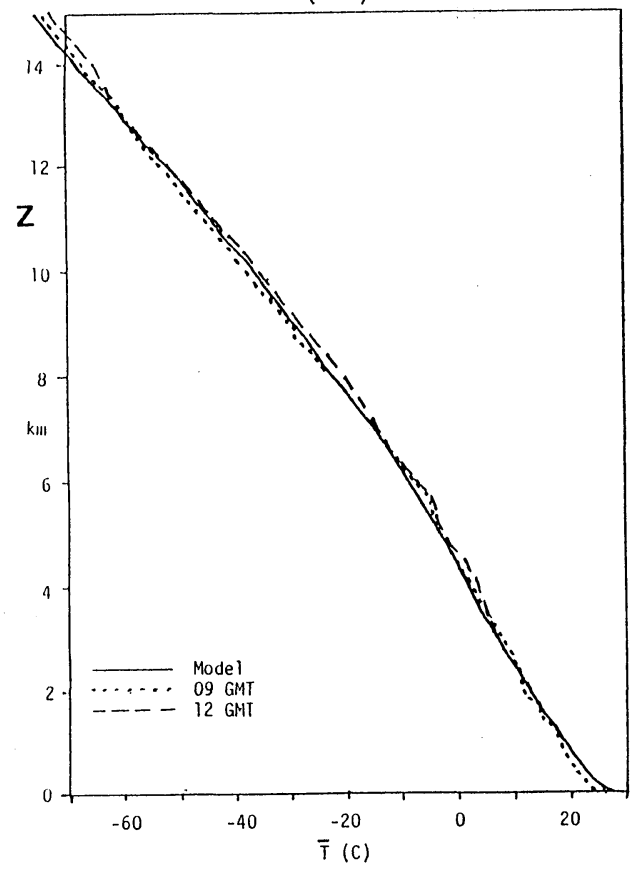

(b)

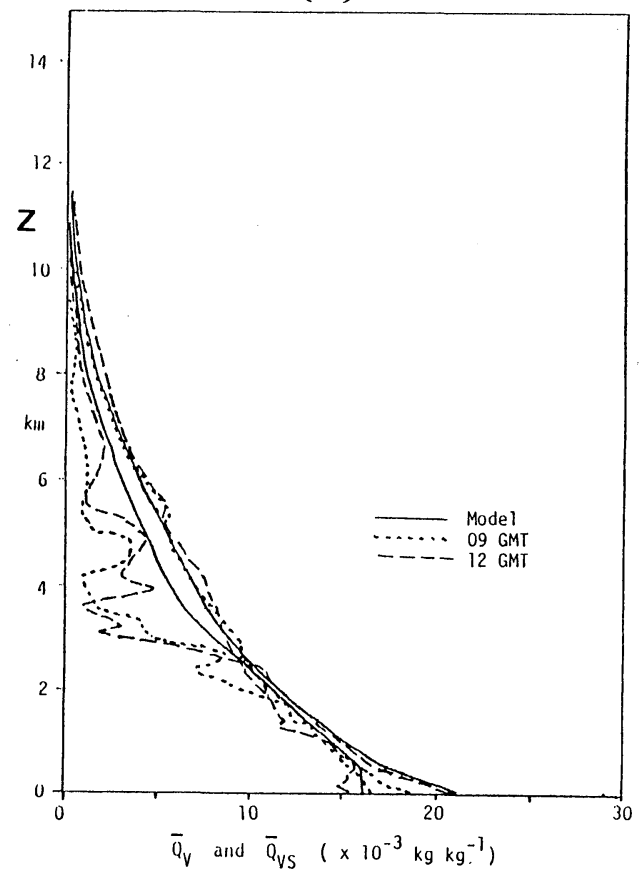

Fig. 5 Vertical profiles of basic stratification; (a) temperature and (b) water vapor mixing ratio and saturated mixing ratio of water vapor (solid lines). The vertical soundings of Oceanographer at 09 GMT and 12 GMT on Sept. 12, 1974 are denoted by dotted and dashed lines, respectively. Note that the melting level is located at about $4.2 \mathrm{~km}$. 
(a)

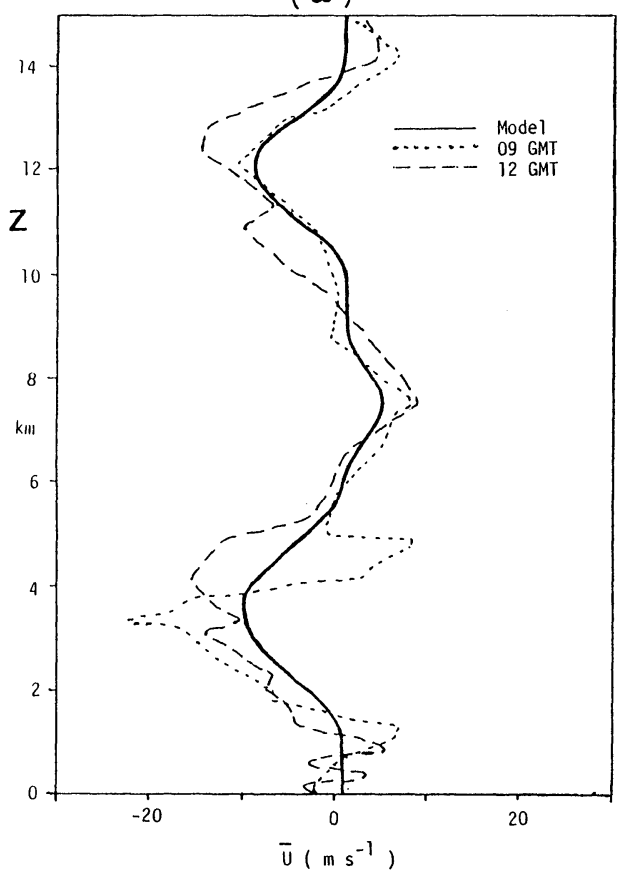

( b )

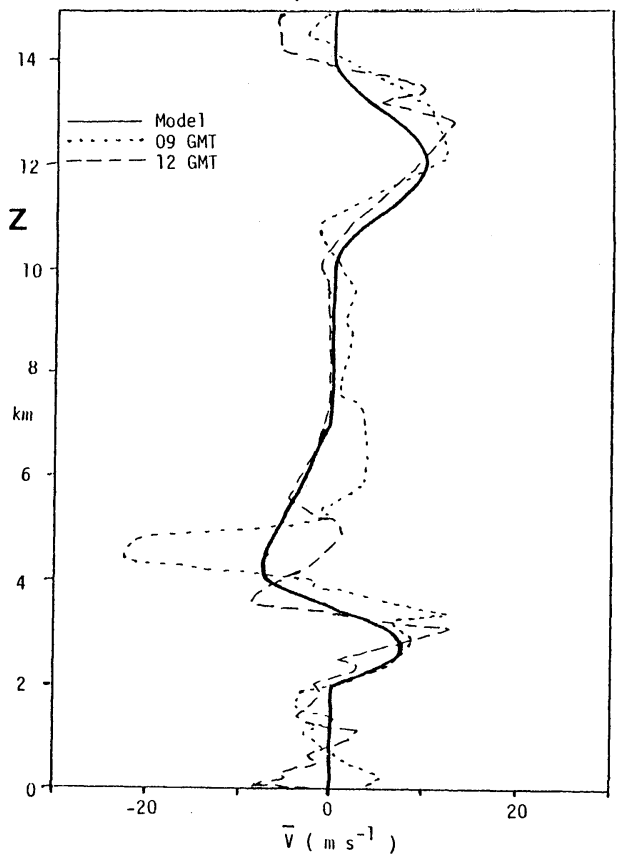

Fig. 6 Vertical profiles of basic winds; (a) $\bar{U}$ and (b) $\bar{V}$.

is a jet profile of $\bar{U}$ in the middle layer. Such a jet profile is often observed when TSLs develop (Mansfield, 1977).

The initial impulse is given as follows;

$$
\theta^{\prime}=\left\{\begin{array}{c}
\Delta T \cos (\pi x / 6) \cos \{\pi(k-7) / 6\}, \\
\text { in }-3 k m<x<3 k m \\
\text { and } 4 \frac{1}{2} \leqq k \leqq 9 \frac{1}{2} \\
0 \quad, \text { otherwise. }
\end{array}\right.
$$

The initial amplitude $\Delta T$ is adopted to be $1.5 \mathrm{~K}$. The initial humidity in this impulse domain is assumed to be saturated and no cloud water exists initially.

\section{2-7. Large-scale convergence/divergence}

The TSLs are sometimes enhanced by largescale wave disturbances and these two interact each other. However, here, interaction between them is assumed to be one-way from the largescale motion to the TSL and the large-scale motion is specified independently of the activity of the TSL.

$F_{C}$ in (1) produces the large-scale convergent/ divergent motion and is defined by

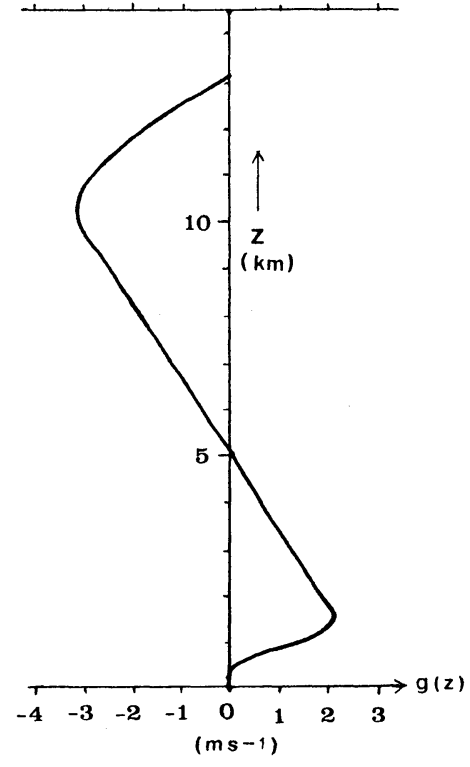

Fig. 7 Vertical profiles of the function $g(z)$.

$$
F_{C}=f(x) g(z) h(t) / t_{*} .
$$

Here the function $f(x)$ is 1 for $-L / 2<x<-X$, $-\sin (\pi x / 2 X)$ for $-X<x<X$ and -1 for $X<x<L /$ 2 where $X$ is given as $20 \mathrm{~km}$. The function $g(z)$ is a function of $z$ which satisfies the mass con- 
servation and given in Fig. 7. This profile is determined by assuming that $2 g(z) / 100 \mathrm{~km}$ corresponds to the combined divergence in Fig. 12 of Gamache and Houze (1982). The function $h(t)$ is 1 for $0<t<t_{*}$ and 0 for $t>t_{*}$, where $t_{*}$ is a duration time of the imposed forcing and assumed to be 30 minutes. In our model $u^{\prime}$ at the lateral boundaries are fixed after $t_{*}$, while $u^{\prime}$ in the inner domain can be changed by the inner dynamics. Thus, the wind profile of $g(z)$ corresponds to that of $u^{\prime}$ at $x=-L / 2$ after $t>t_{*}$.

\section{Numerical study of the TSL}

\section{3-1. Temporal variations}

Fig. 8 shows temporal variations of the maximum and minimum values of $w$ ( $w_{\max }$ and $\left.w_{\min }\right)$ in the model domain. Note that nearly quasi-steady states are attained after about 2 hours.

Fig. 9 shows flow patterns and distributions of $Q_{C}, Q_{R}$ (solid lines), $Q_{G}$ (dashed lines), $Q_{H}$ (dashed-dotted lines) and $\theta^{\prime}$ (solid lines)

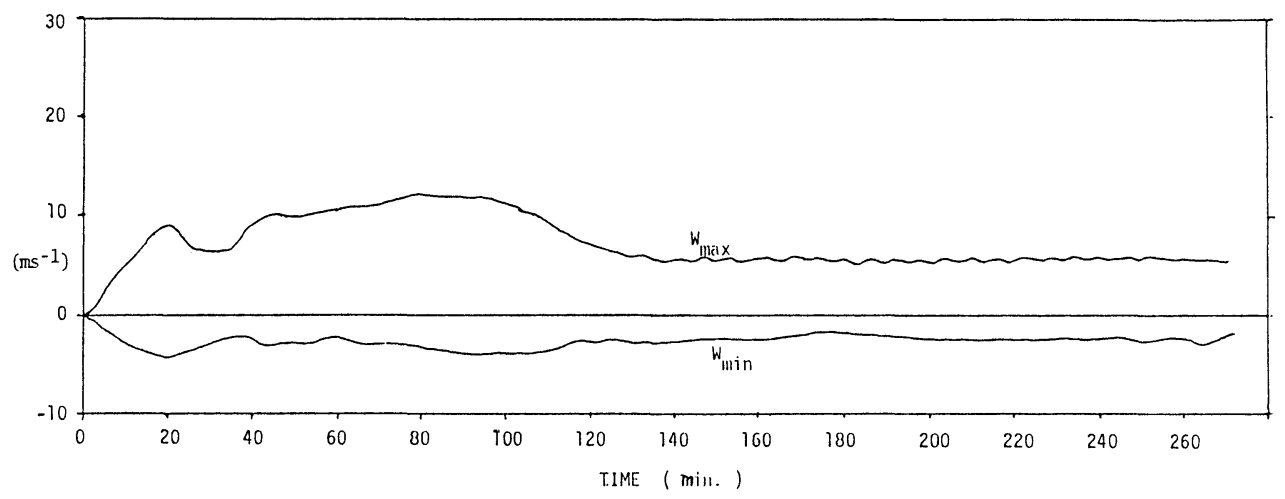

Fig. 8 Temporal variations of the maximum and minimum values of $w\left(W_{\max }\right.$ and $W_{\min }$; $\mathrm{m} \mathrm{s}^{-1}$ ).

(a)

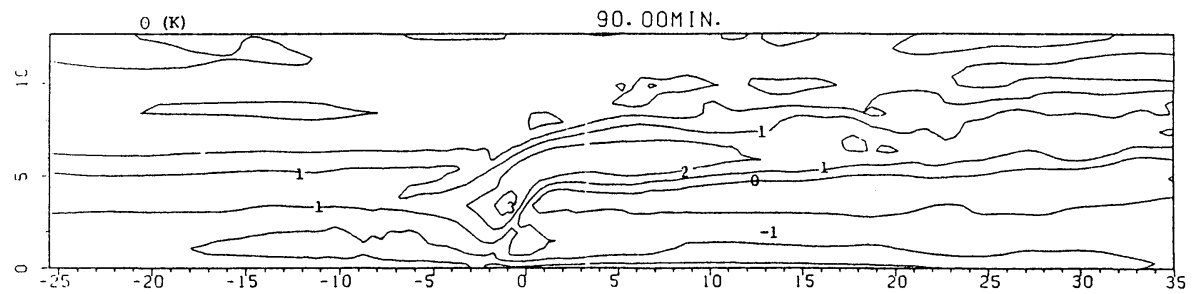

$\begin{array}{ll}Q_{c}, Q_{R}, Q_{C} Q_{H} & 90.00 M I N .\end{array}$
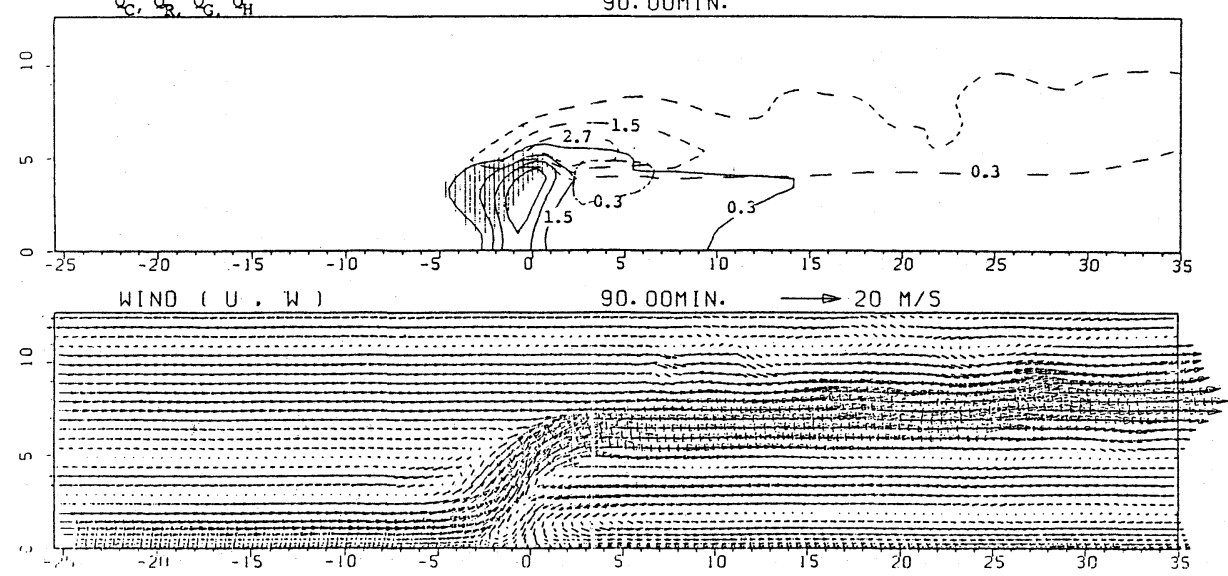
(b)
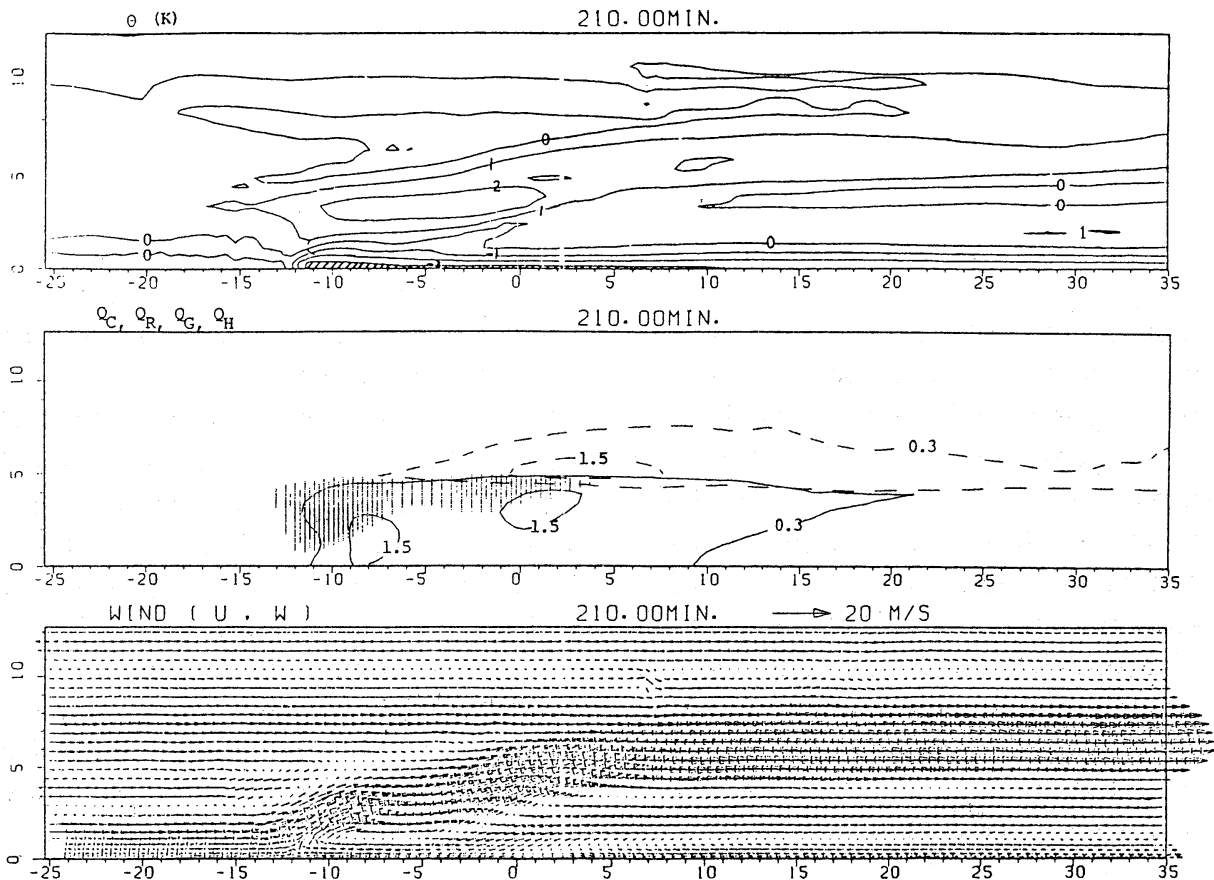

(c)

270. OOMIN.

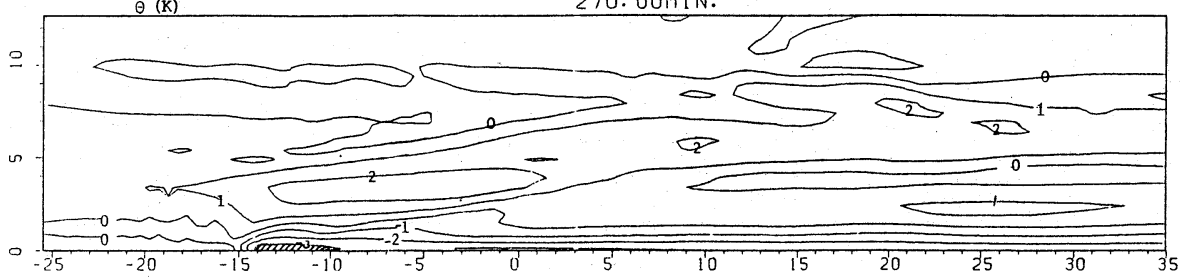

$Q_{C}, Q_{R}, Q_{G}, Q_{H}$

270. 00M IN
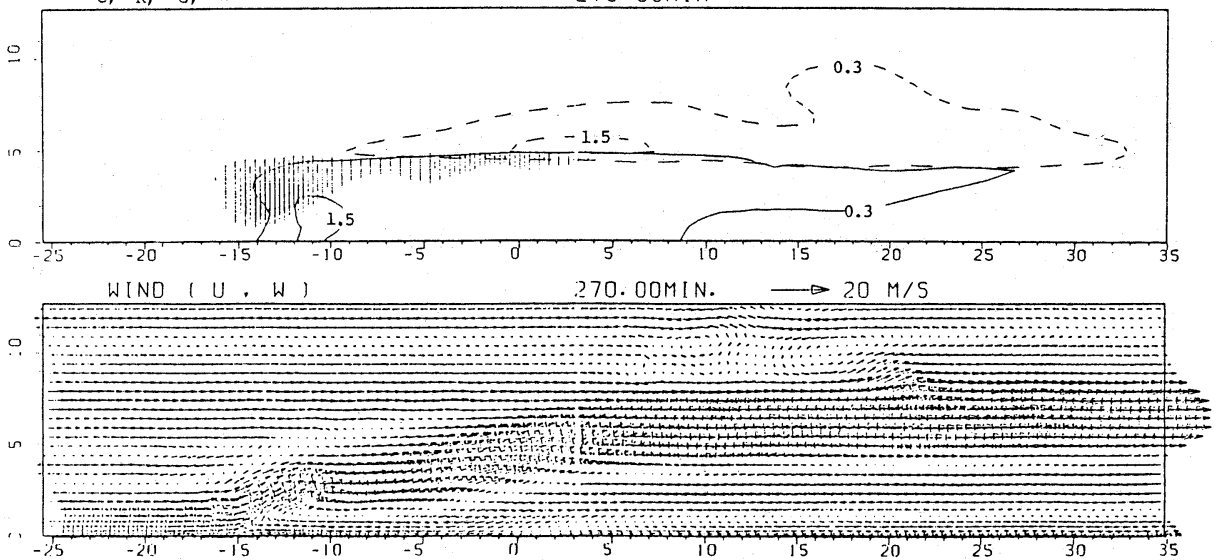

Fig. 9 Flow patterns and distributions of $Q_{C}$ (The regions where $Q_{C}$ is greater than $3 \times 10^{-4}$ $\mathrm{kg} \mathrm{kg}^{-1}$ are shaded.), $Q_{R}$ (solid lines), $Q_{G}$ (dashed lines), $Q_{H}$ (dashed-dotted lines) and $\theta^{\prime}$ at (a) 90 , (b) 210 and (c) 270 minutes, respectively. Contour lines of $Q_{R}, Q_{G}$ and $Q_{H}$ denote $0.3,1.5,2.7,3.9,5.1$ and so on $\left(\times 10^{-3} \mathrm{~kg} \mathrm{~kg}^{-1}\right)$. The regions where $\theta^{\prime}$ is below $-3 \mathrm{~K}$ are shaded. 
at (a) 90, (b) 210 and (c) 270 minutes, respectively. The regions where $Q_{c}$ is greater than 0.3 $\times 10^{-3} \mathrm{~kg} \mathrm{~kg}^{-1}$ are shaded. Contour lines of $Q_{R}, Q_{G}$ and $Q_{H}$ denote $0.3,1.5,2.7,3.9$ (x $10^{-3} \mathrm{~kg} \mathrm{~kg}^{-1}$ ) and so on. Contour lines of $\theta^{\prime}$ are drawn every $1 \mathrm{~K}$ and the regions for $\theta^{\prime}$ being below $-3 \mathrm{~K}$ are shaded. $Q_{I}$ is always less than $0.3 \times 10^{-3} \mathrm{~kg} \mathrm{~kg}^{-1}$.

Both convective and stratiform regions are well simulated in Fig. 9. The convective region has a strong updraft and a weak downdraft in the rear. Its extension in Fig. 9(c) is considered to be between $-15 \mathrm{~km}$ and $5 \mathrm{~km}$, so that the horizontal scale of the convective region is about $20 \mathrm{~km}$. The warm region extends in the updraft region, while the cold region is found near the surface. The updraft in this region tilts largely and the angle from the horizontal is about 15 degrees in the quasi-steady. stage ( $b$ and $c$ ). This slant updraft is similar to that in Fig. 2(b) and those analyzed by LeMone et al. (1984a).
On the other hand, the stratiform region is formed in the rear of the convective region. The motions seem to be nearly uniform in the horizontal direction, except some oscillations in the upper layer. There are three layers with strong horizontal winds; the rightward wind in the anvil cloud, the leftward one at the height of 1-4 km and the rightward one on the surface. These layer structures of winds are similar to those in Fig. 2. Graupel forms the anvil cloud above the melting level and rain is present below it. They expand in the windward direction. The warm regions are found above the melting level and at the height of $1-3 \mathrm{~km}$ in the subcloud layer, while the cold regions are around the melting level and on the surface.

Fig. 10 shows vertical sections of (a) $w$, (b) $\theta$ and (c) $Q_{v}$ at 270 minutes. From (a) weak updraft above the melting level and weak downdraft below it are found in the stratiform region. Thus the separate circulations in this region are

(a)
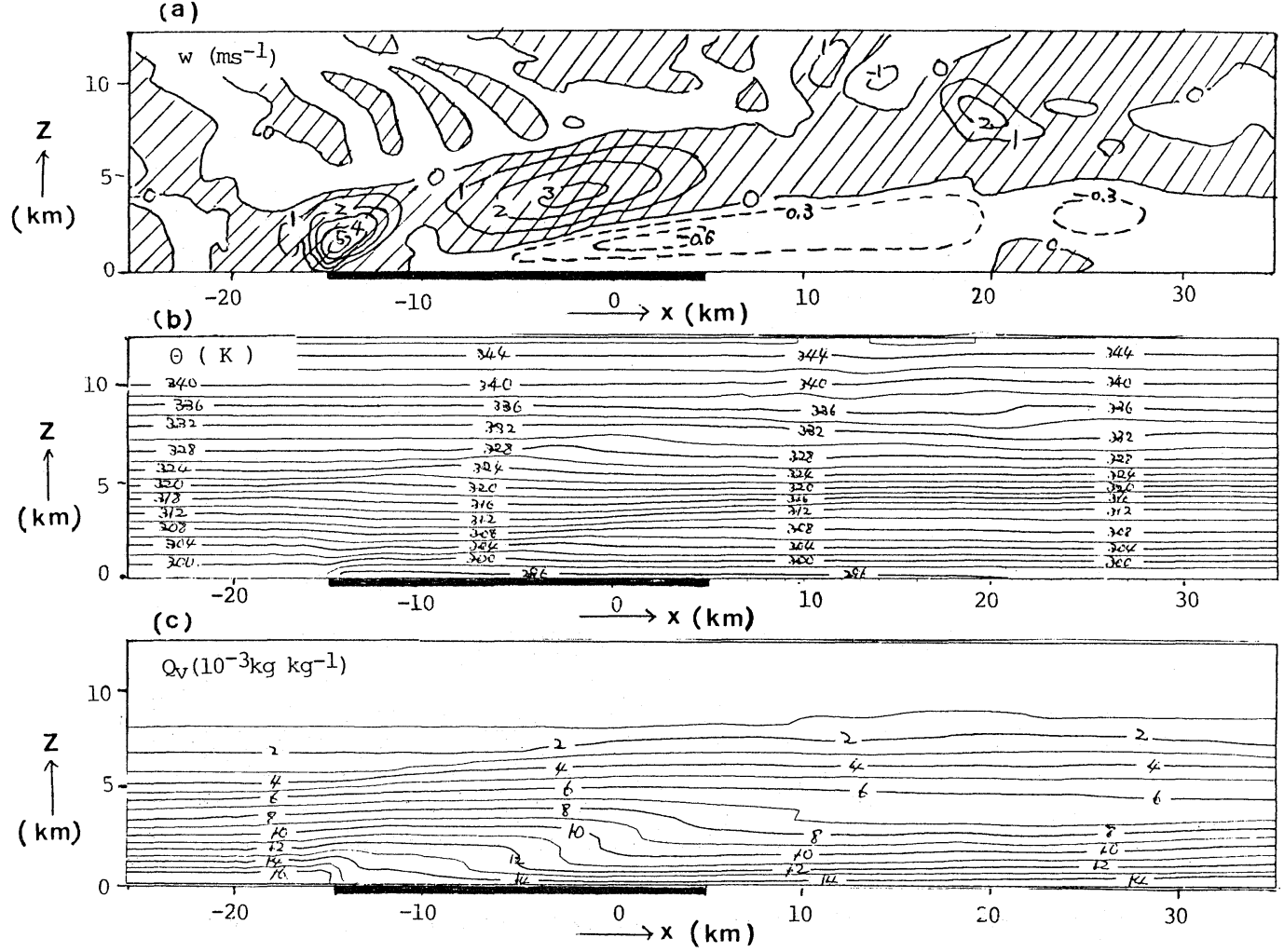

Fig. 10 Vertical sections of (a) $w\left(\mathrm{~ms}^{-1}\right.$, the solid contour interval is $1 \mathrm{~ms}^{-1}$, while the dashed one is 0.3 $\left.\mathrm{ms}^{-1}\right)$, (b) $\theta$ (K; the contour interval is $2 \mathrm{~K}$ ) and (c) $Q_{V}\left(10^{-3} \mathrm{~kg} \mathrm{~kg}^{-1}\right)$ at 270 minutes. The updraft regions are shaded. The convective region is considered to be between $-15 \mathrm{~km}$ and $5 \mathrm{~km}$. 


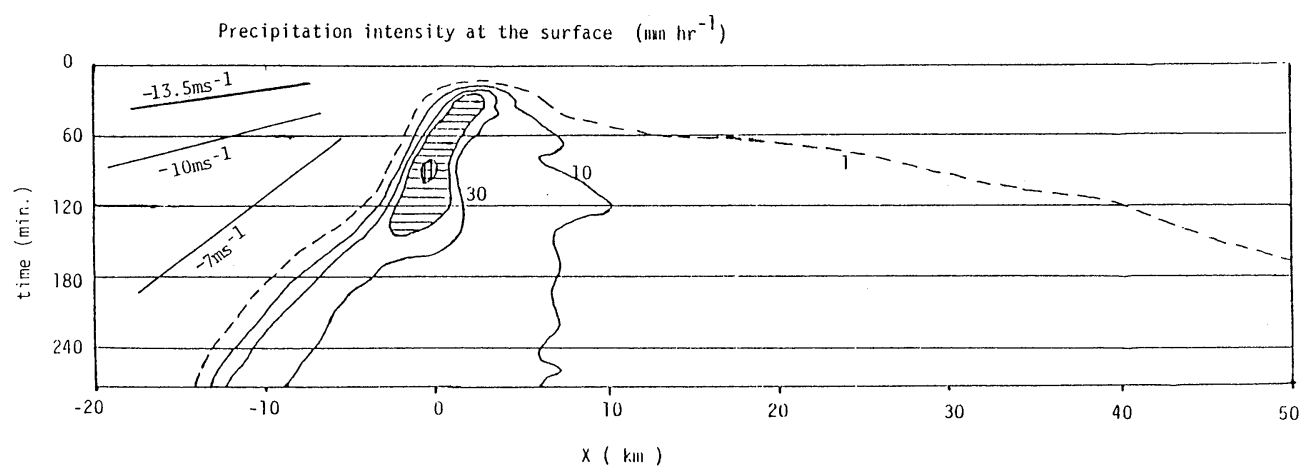

Fig. 11 Temporal variation of precipitation intensity at the surface $\left(\mathrm{mm} \mathrm{hr}^{-1}\right)$. The regions where precipitation intensity exceeds $50 \mathrm{~mm} \mathrm{hr}^{-1}$ are shaded. The straight lines denote propagation speeds relative to the surface.

well simulated in this model. Strong jumps of $\theta$ and $Q_{V}(b$ and $c)$ are seen around $x=-15 \mathrm{~km}$ on the surface and reduced in magnitude with height.

Fig. 11 shows temporal variations of the precipitation intensity $\left(\mathrm{mm} \mathrm{hr}^{-1}\right)$ on the surface. If we assign a value of $10 \mathrm{~mm} \mathrm{hr}^{-1}$ of the precipitation intensity in order to distinguish convective precipitation from stratiform one, both precipitations are well simulated in the sense that stratiform precipitation extends to a wide area compared with convective one. The convective system simulated in this model moves leftward with the propagation speed of $7 \mathrm{~m} \mathrm{~s}^{-1}$ relative to the surface. This speed is smaller than the observed one $\left(13.5 \mathrm{~m} \mathrm{~s}^{-1}\right)$ and even the maximum value of the leftward wind velocity $\left(10 \mathrm{~m} \mathrm{~s}^{-1}\right)$. Thus this convective system has a steering level in the troposhere and is not the strict TSL if the TSL is characterized as a rapid propagating cloud cluster.

\section{3-2. The distributions of physical quantities on the surface}

Fig. 12 (a), (b), (c) and (d) denote the distributions of precipitation intensity and pressure (hPa), $Q_{V}$ and relative humidity ( $\left.\mathrm{Rh}, \%\right)$, wind components $\tilde{u}, \tilde{v}$ and the friction velocity $u_{*}$, and temperature $\left({ }^{\circ} \mathrm{C}\right)$, sensible heat flux $(\mathrm{SH}$, $\mathrm{W} \mathrm{m^{-2 }}$ ) and latent heat flux $\left(\mathrm{LH}, \mathrm{W} \mathrm{m}^{-2}\right)$, respectively, on the surface at 270 minutes. The change of wind direction is seen at $x=-17 \mathrm{~km}$, denoted by triangles. Behind it, gust wind and sharp drops of temperature and water vapor mixing ratio are found, reaching about $-12 \mathrm{~m}$ $\mathrm{s}^{-1}, 3.5 \mathrm{~K}$ and $2 \times 10^{-3} \mathrm{~kg} \mathrm{~kg}^{-1}$, respectively. On the other hand, the pressure rise is gradual and weak, reaching only $0.6 \mathrm{hPa}$. The large amounts of sensible and latent heat fluxes are seen under the cold dome, reaching about 130 $\mathrm{W} \mathrm{m}^{-2}$ and $450 \mathrm{~W} \mathrm{~m}^{-2}$, respectively.

Compared with results of the composite analysis done by Johnson and Nicholls (1983), simulated drops of temperature and $Q_{V}$ and pressure rise near the gust front are small. Especially, the pressure ruse is. only a third of the observed one. On the other hand, simulated sensible and latent heat fluxes agree well with observed ones.

\section{3-3. Heat and moisture budgets in the simulated $T S L$}

Now we examine production rates of potential temperature and $Q_{V}$ in the TSL simulated in the model. For simplicity, terms in (9), (15), (16) and (22) are grouped into four terms; an advection term, an instantaneous adjustment term, a production term of precipitating particles and a diffusion term. Productions among water vapor, cloud water and cloud ice enclosed by the dotted line in Fig. 3 take place during one time step and so are called the instantaneous adjustment term. In this term condensation of water vapor and evaporation of cloud water are dominant, since the amount of cloud ice is very small below about $10 \mathrm{~km}$. The production term of precipitating particles denotes the production terms of rain, graupel and hail.

Fig. 13 shows the vertical distributions of (a) the advection term, (b) the instantaneous 
(a) Precipitation intensity (PI) and pressure

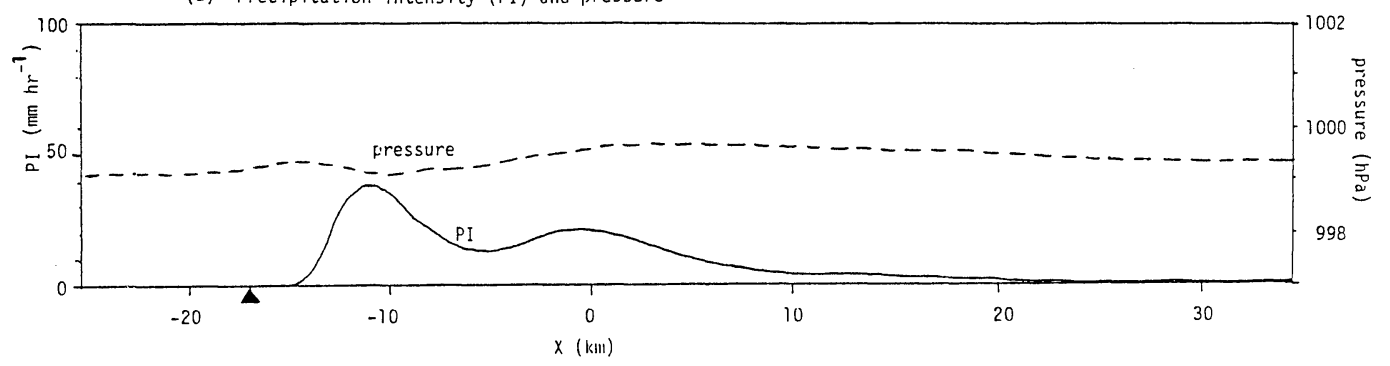

(b) $Q_{V}$ and relative humidity (RH)

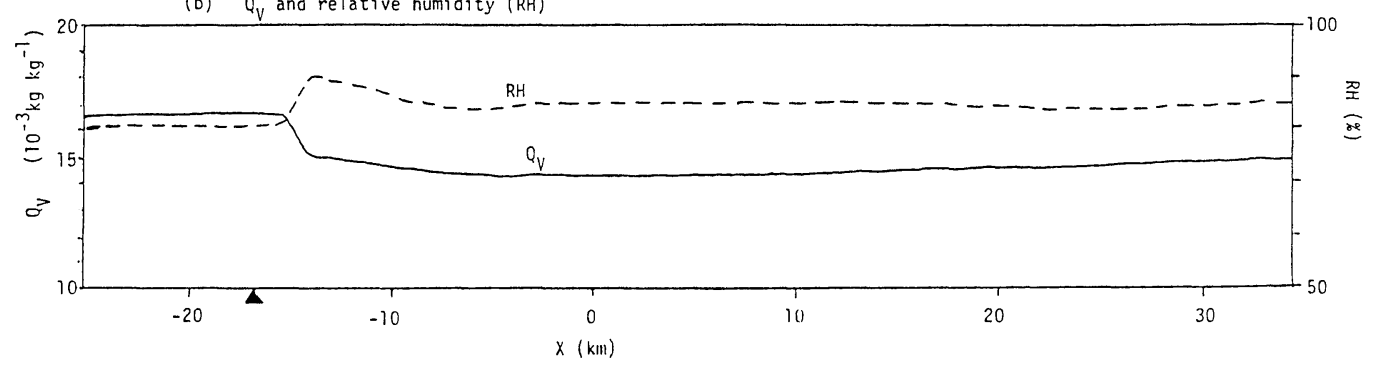

(c) $\widetilde{u}, \widetilde{v}$ and $u_{*}$

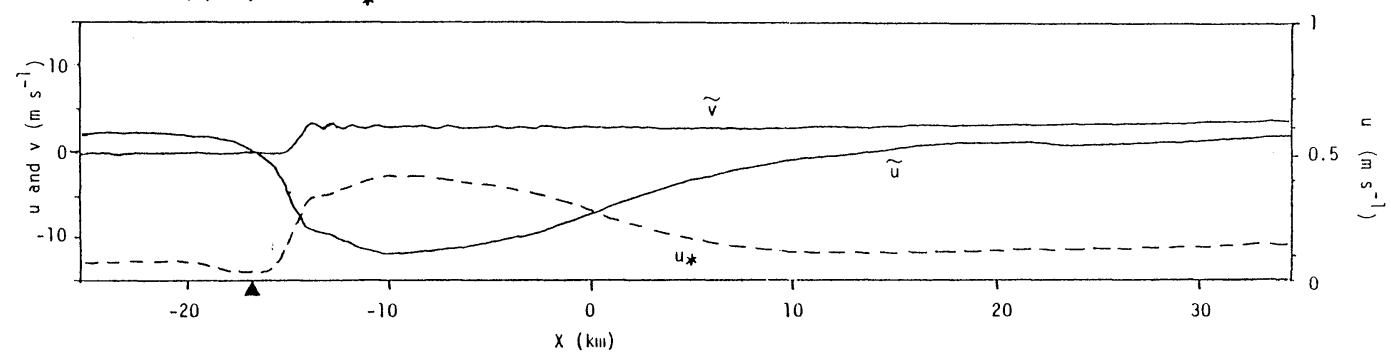

(d) Tenperature, sensible heat flux (SH) and latent heat flux (LH)

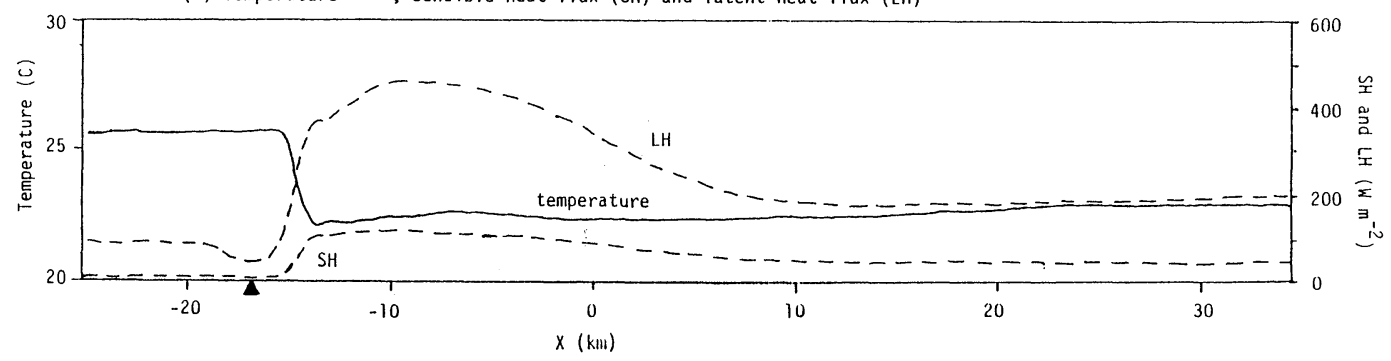

Fig. 12 Distributions of (a) precipitation intensity and pressure (hPa), (b) $Q_{V}$ and relative humidity (\%), (c) winds $\tilde{u}$ and $\tilde{\imath}$ and the friction velocity $u_{*}$ and (d) temperature $\left({ }^{\circ} \mathrm{C}\right)$ and latent and sensible heat fluxes $\left(\mathrm{W} \mathrm{m}^{-2}\right)$ on the surface at 270 minutes.

adjustment term and (c) the production term of precipitating particles of potential temperature, and (d) the advection term, (e) the instantaneous adjustment term and (f) the production term of precipitating particles of wäter vapor at 270 minutes. Heating and moistening are shaded.
Note that the units in (d) and (e) are different from that in (f) and greater by 10 times.

In the convective cloud, condensation of water vapor is mostly responsible for heating and drying, while the upward advection is responsible for cooling and moistening. On the 

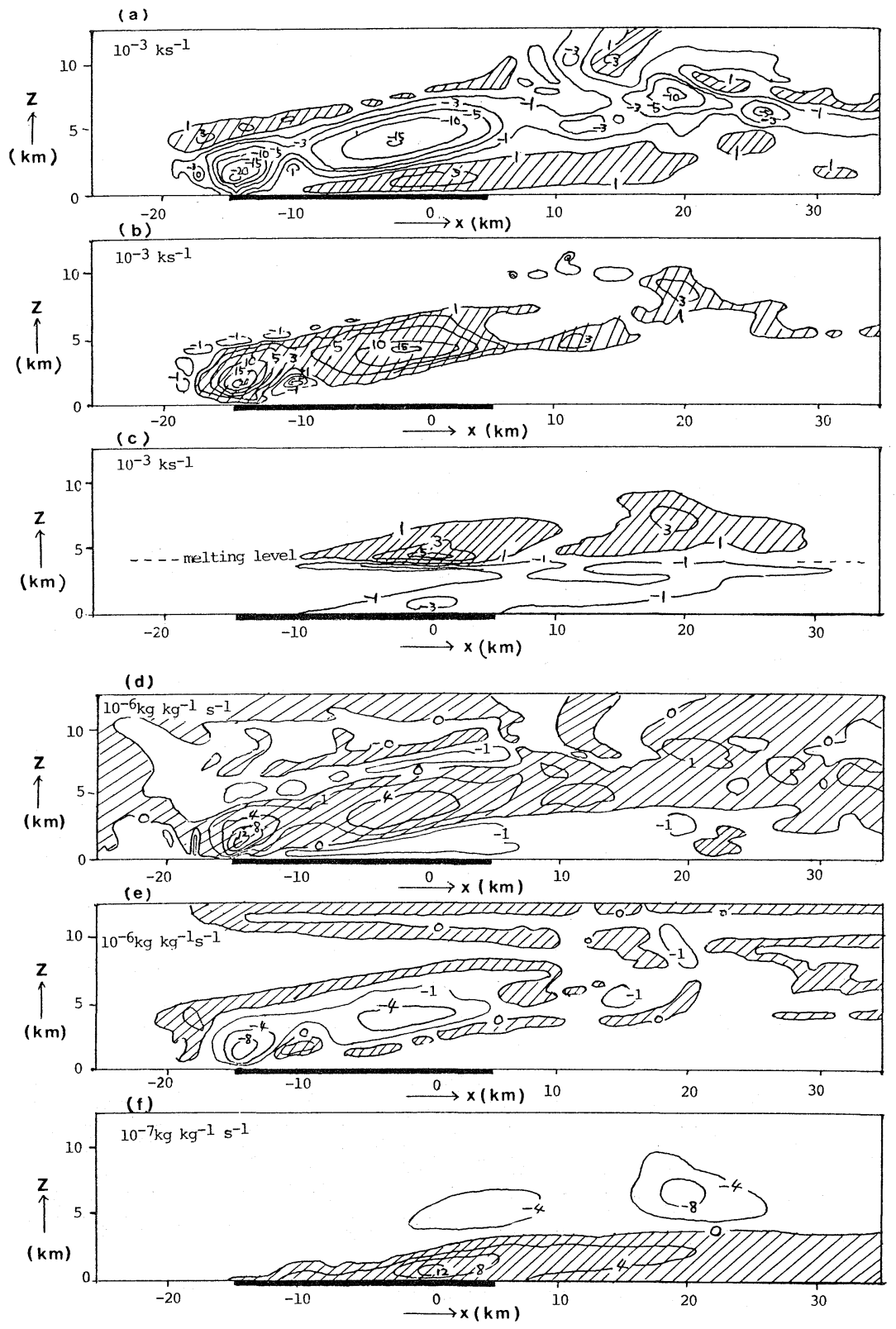

Fig. 13 Vertical distributions of (a) the advection term, (b) the instantaneous adjustment term, (c) the production term of precipitating particles of potential temperature, and (d) the advection term, (e) the instantaneous adjustment term, (f) the production term of precipitating particles of water vapor at 270 minutes. Heating and moistening are shaded. The contour lines are drawn unevenly as $-8,-4,-1,0,1,4,8$ and 12 in (d) and (e). The unit in (f) is smaller than those in (d) and (e).

other hand, in the anvil cloud of the stratiform region, heating and drying are due to both condensation of water vapor and the production term of precipitating particles, and cancelled by cooling and moistening due to the upward advection. Among the production term of precipitating particles, melting of graupel is responsible for cooling near the melting level and forms the 


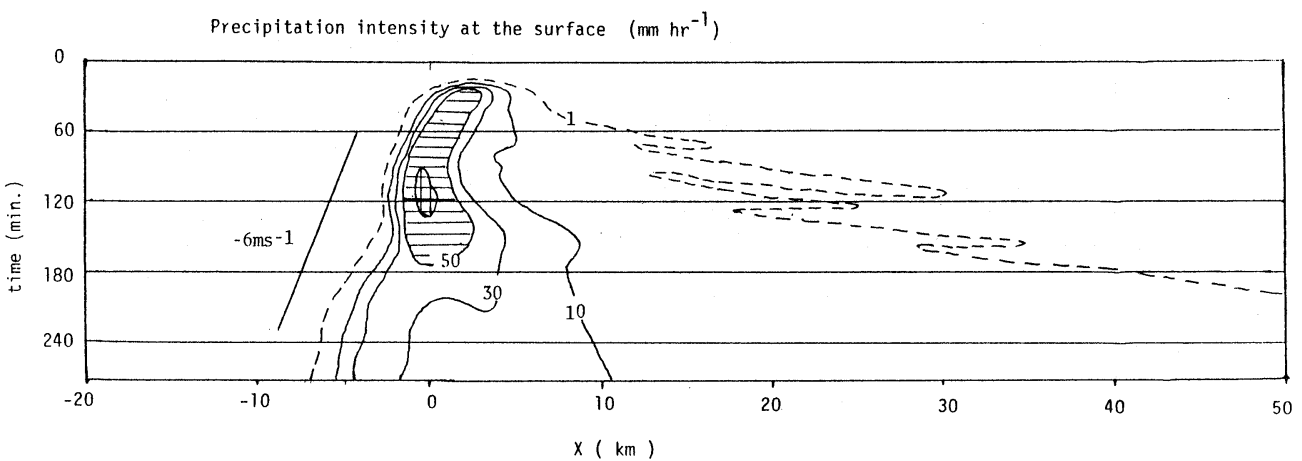

Fig. 14 Same as Fig. 11 except for the warm rain model.
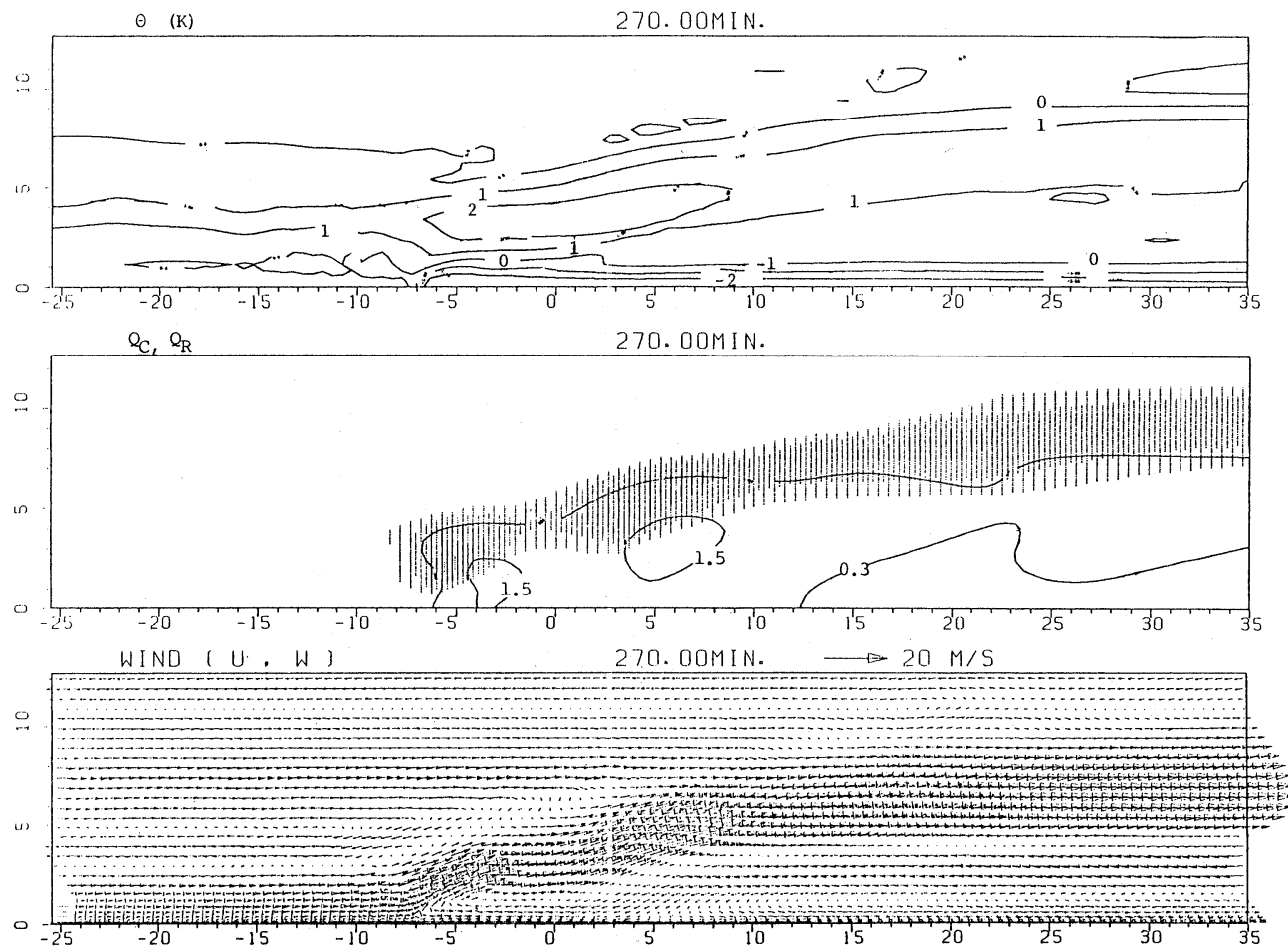

Fig. 15 Same as Fig. 9(c) except for the warm rain model.

cold region as seen in Fig. 9(c). Heating above the melting level is mainly due to accretion of cloud water by graupel and deposition of water vapor by graupel. Drying above the melting level is mostly due to depositon of water vapor by graupel. In the subcloud layer, cooling and moistening are brought by evaporation of rain, and counter warming and drying due to the downward advection.

There is a small amount of cloud water above the melting level in the stratiform region, al- though cloud water seems to be produced by condensation of water vapor as seen in Fig. 13(b) and (e). This is mainly due to efficient accretion of cloud water by graupel, since the number of graupel adopted in this model is very large.

\section{3-4. Numerical study with the warm rain model}

In this subsection, some results of simulation of the TSL are shown when the model without ice - a warm rain model - is used. The model discussed in previous subsections is simply 


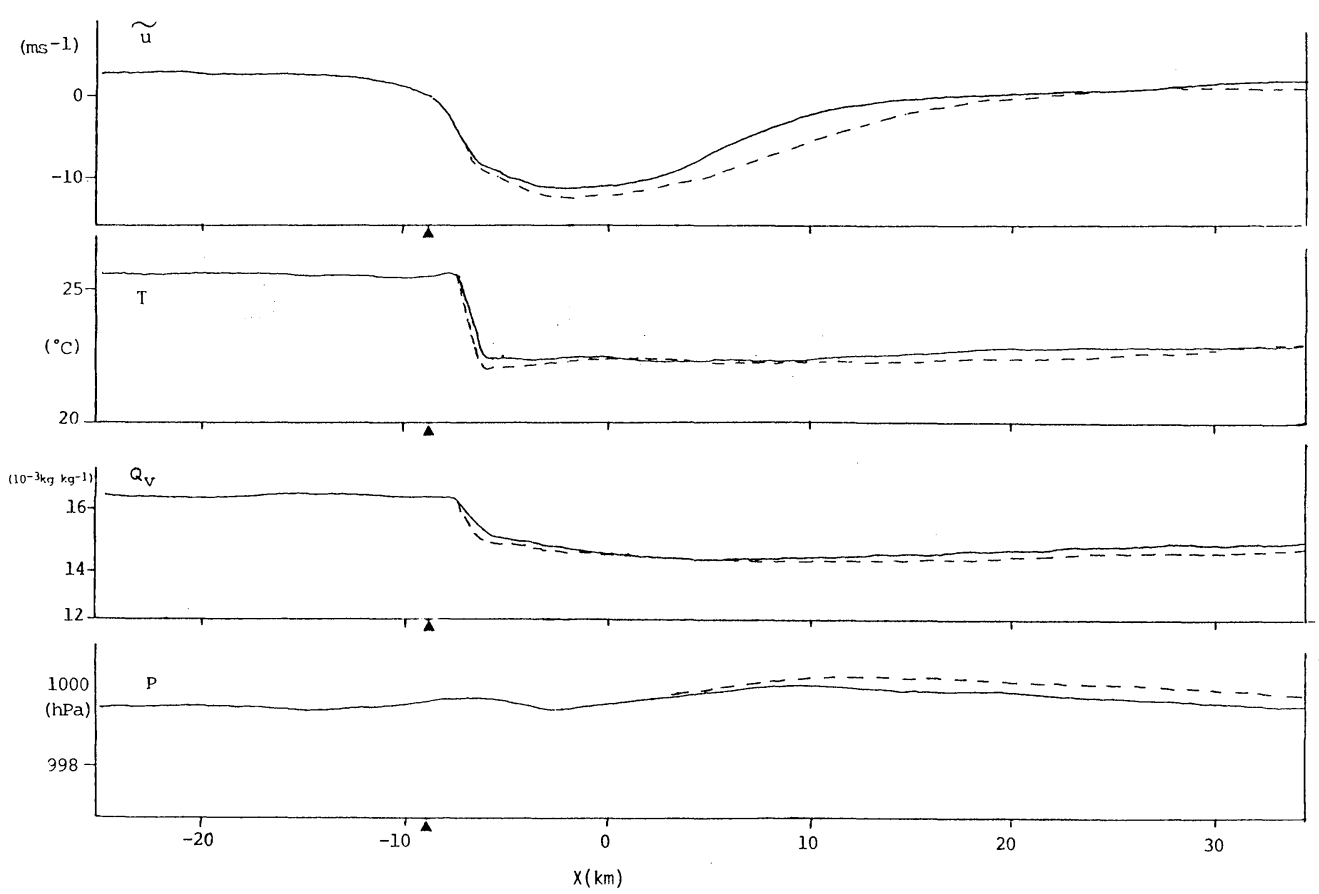

Fig. 16 Distributions of $\tilde{u}$, temperature, $Q_{V}$ and pressure on the surface at 270 minutes for the warm rain model (solid lines). The dashed lines indicate those for the cold rain model.

called a cold rain model.

Fig. 14 shows temporal variations of precipitation intensity on the surface. Both convective and stratiform precipitations are obtained and similar to Fig. 11 of the cold rain model. The simulated convective system moves leftward relative to the surface with the speed of $6 \mathrm{~m} \mathrm{~s}^{-1}$. Its propagation speed is slightly small compared with that in Fig. 11. Soong and Chen (1984) also obtained small propagation speed of the TSL when they used the warm rain model. This suggests that it may be difficult to get fast propagation of the TSL when the warm rain model is used.

Fig. 15 shows flow patterns and distributions of $Q_{C}, Q_{R}$ and $\theta^{\prime}$ at 270 minutes. There is no cold region in the middle layer, because there is no melting level in the warm rain model. To be surprised, flow patterns and extension of the anvil cloud are similar to those in Fig. 9. However, it is thought that this mesoscale circulation might not be so robust when the basic states are changed, since it is not seen in Yamasaki (1984)'s warm rain model.

Fig. 16 denotes the distributions of $\tilde{u}$, temperature, $Q_{V}$ and pressure on the surface at
270 minutes. The quantities of the warm rain model are drawn by solid lines, while those of the cold rain model are given by dashed lines. Generally, gust wind, drops of temperature and $Q_{V}$ and the pressure rise of the warm rain model are small. Among them, the pressure rise is small in the whole stratiform region.

This small pressure rise in the stratiform region of the warm rain model might result in slow propagation of the TSL. The surface pressure is determined mainly hydrostatically by the vertical distribution of potential temperature. Since temperature distribution near the surface is similar in both cases (see Figs. 9 and 15), the large pressure rise in the cold rain model might be due to the cold region near the melting level. In this sense, ice particles are necessary to make the large pressure rise on the surface and to proceed the convective system fast.

\section{Conclusions}

2-dimensional numerical study of a tropical squall-line cluster (TSL) is performed to simulate (1) convective and stratiform regions of the TSL, (2) the slant updraft in the convective region 
and the separate circulations in the stratiform region consisting of the weak updraft in the anvil cloud and the weak downdraft below it, (3) sharp jumps of physical quantities at the gust front on the surface and (4) fast propagation of the convective system.

The convective and stratiform regions are well simulated. The shallow slant updraft in the convective region, the updraft in the anvil cloud and weak downdraft below it are also simulated. Sharp jumps of winds, temperature, $Q_{V}$, pressure and heat fluxes near the gust front on the surface are also obtained, although some are weak in intensity compared with the observations. Especially the pressure rise is very small. Fast propagation of the TSL is not well simulated in our model.
The cold region near the melting level in the stratiform region is produced by melting graupel and seems to be important to make a large pressure rise on the surface when results of the cold rain model are compared with those of the warm one. However, this pressure rise is not sufficient to proceed the convective system very fast. Some mechanisms are necessary to account for fast propagation of the TSL.

\section{Acknowledgements}

The author wishes to express hearty thanks to Profs. T. Asai and R. Kimura of Ocean Research Institute, University of Tokyo, Prof. Y. Ogura, University of Illinois, Prof. T. Takeda, University of Nagoya and two anonymous referees for giving him many comments.

\section{Appendix}

Production rates of the microphysical processes

List of Symbols

\begin{tabular}{|c|c|c|c|c|c|}
\hline Notation & Production rate & from & to & & Value \\
\hline$P_{R A C C}$ & Accretion & $Q_{C}$ & $Q_{R}$ & $E_{R C} \quad Q_{C}$ & $E_{\mathrm{RC}}=1$ \\
\hline$P_{R A C I}$ & Accretion & $Q_{I}$ & $Q_{G}$ & $E_{R I} \quad Q_{I} \quad F(a, b ; R)$ & $\mathrm{E}_{\mathrm{RI}}=1$ \\
\hline$P_{G A C C}$ & Accretion & $Q_{C}$ & $Q_{G}$ & $E_{G C} \quad Q_{C} \quad F(c, d ; G)$ & $\mathrm{E}_{\mathrm{GC}}=1$ \\
\hline$P_{G A C R}$ & Accretion & $Q_{R}$ & $Q_{G}$ & $E_{G R} \quad G(R, G)$ & $\mathrm{E}_{\mathrm{GC}}=1$ \\
\hline$P_{I A C R}$ & Accretion & $Q_{R}$ & $Q_{G} / Q_{H}$ & $\frac{\pi^{2} E_{I R} n_{O R} a Q_{I} \rho_{R} \Gamma(b+6)}{24 m_{I} \lambda_{R}^{b+6}}\left(\frac{\rho_{0}}{\bar{\rho}}\right)^{1 / 2}$ & $\mathrm{E}_{\mathrm{IR}}=1$ \\
\hline$P_{I A C C}$ & Accretion & $Q_{C}$ & $Q_{G}$ & $E_{I C} \quad Q_{C} \quad Q_{I} \quad \bar{\rho} \frac{\pi R_{I}^{2} U_{I}}{m_{I}}$ & $\begin{array}{l}\mathrm{E}_{\mathrm{IC}}=1 \\
\mathrm{R}_{\mathrm{I}}=10^{-5} \mathrm{~m} \\
\mathrm{U}_{\mathrm{I}}=1 \mathrm{~m} \mathrm{~s}^{-1}\end{array}$ \\
\hline$P_{G A C I}$ & Accretion & $Q_{I}$ & $Q_{G}$ & $E_{G I} \quad Q_{I} \quad \exp \left(0.025 T_{c}\right) \quad F(c, d ; G)$ & $\mathrm{E}_{\mathrm{GI}}=0.1$ \\
\hline$P_{G A C I}^{\prime}$ & Accretion & $Q_{I}$ & $Q_{G}$ & $E_{G I} \quad Q_{I} \quad \exp \left(0.025 T_{C}\right) \quad F(c, d ; G)$ & $\mathrm{E}_{\mathrm{GI}}=1$ \\
\hline$P_{H A C C}$ & Accretion & $Q_{C}$ & $Q_{H}$ & $E_{H C} \quad Q_{C} \quad F(h, 1 / 2 ; H)$ & $\mathrm{E}_{\mathrm{HC}}=1$ \\
\hline$P_{H A C R}$ & Accretion & $Q_{R}$ & $Q_{H}$ & $E_{H R} \quad G(R, H)$ & $\mathrm{E}_{\mathrm{HR}}=1$ \\
\hline$P_{H A C I}$ & Accretion & $Q_{I}$ & $Q_{H}$ & $E_{H I} \quad Q_{I}$ & $\mathrm{E}_{\mathrm{HI}}=0.1$ \\
\hline$P_{H A C I}^{\prime}$ & Accretion & $Q_{I}$ & $Q_{H}$ & $E_{H I} \quad Q_{I} \quad F(h, 1 / 2 ; H)$ & $\mathrm{E}_{\mathrm{HI}}=1$ \\
\hline$P_{H A C G}$ & Accretion & $Q_{G}$ & $Q_{H}$ & $E_{H G} \quad G(G, H)$ & $\mathrm{E}_{\mathrm{HG}}=0.1$ \\
\hline$P_{H A C G}^{\prime}$ & Accretion & $Q_{G}$ & $Q_{H}$ & $E_{H G} \quad G(G, H)$ & $\mathrm{E}_{\mathrm{HG}}=1$ \\
\hline$P_{R A U T}$ & Autoconversion & $Q_{C}$ & $Q_{R}$ & $\left(Q_{C}-Q_{C O}\right)$ & $\begin{array}{l}\mathrm{a}_{\mathrm{R}}=10^{-3} \mathrm{~s}^{-1} \\
\mathrm{Q}_{\mathrm{CO}}=10^{-3}\end{array}$ \\
\hline$P_{G A U T}$ & Autoconversion & $Q_{I}$ & $Q_{G}$ & $a_{G} \quad \exp \left(0.025 T_{C}\right)\left(Q_{I}-Q_{I O}\right)$ & $\begin{array}{l}\mathrm{a}_{\mathrm{G}}=10^{-3} \mathrm{~s}^{-1} \\
\mathrm{Q}_{\mathrm{IO}}=5 \times 10^{-4}\end{array}$ \\
\hline
\end{tabular}




\begin{tabular}{|c|c|c|c|c|c|}
\hline \multirow[t]{2}{*}{$P_{H A U T}$} & Autoconversion & $Q_{G}$ & $Q_{H}$ & $a_{H} \quad \exp \left(0.09 T_{C}\right) \quad\left(Q_{G}-Q_{G O}\right)$ & $a_{H}=10^{-3} \mathrm{~s}^{-1}$ \\
\hline & & & & & $\mathrm{Q}_{\mathrm{GO}}=3 \times 10^{-3}$ \\
\hline \multirow[t]{2}{*}{$P_{G F R}$} & Freezing & $Q_{R}$ & $Q_{G}$ & $20 \pi^{2} B^{\prime} n_{O R}\left(\frac{\rho_{w}}{\bar{\rho}}\right)$ & $\mathrm{A}^{\prime}=0.66$ \\
\hline & & & & $\times\left\{\exp \left(-A^{\prime} T_{c}\right)-1\right\} \lambda_{R}^{-7}$ & $\mathrm{~B}^{\prime}=100$ \\
\hline$P_{G D E P}$ & Deposition & $Q_{V}$ & $Q_{G}$ & $\left(S_{i}-1\right) \quad H(c, d, G) / J\left(L_{s}, Q_{V S I}\right)$ & \\
\hline$P_{H D E P}$ & Deposition & $Q_{V}$ & $Q_{H}$ & $\left(S_{i}-1\right) \quad H(h, 1 / 2 ; H) / J\left(L_{s}, Q_{V S I}\right)$ & \\
\hline$P_{G M L T}$ & Melting & $Q_{G}$ & $Q_{R}$ & $I\left(Q_{V S_{I}}\right) H(c, d ; G) / L_{f}$ & \\
\hline$P_{H M L T}$ & Melting & $Q_{H}$ & $Q_{R}$ & $I\left(Q_{V S I}\right) H(h, 1 / 2 ; H) / L_{f}$ & \\
\hline$P_{R E V P}$ & Evaporation & $Q_{R}$ & $Q_{V}$ & $(1-S) \quad H(a, b ; R) / J\left(L_{v}, Q_{V S}\right)$ & \\
\hline
\end{tabular}

Here

$$
\begin{gathered}
F(x, y ; Z)=\frac{\pi n_{0 Z} x \Gamma(y+3)}{4 \lambda_{Z}^{y_{Z}^{+3}}}\left(\frac{\rho_{0}}{\bar{\rho}}\right)^{1 / 2}, \\
G(X, Y)=\pi^{2} n_{0 X} n_{0 Y}\left|U_{X}-U_{Y}\right|\left(\frac{\rho_{X}}{\bar{\rho}}\right) \\
\left(\frac{5}{\lambda_{X}^{6} \lambda_{Y}}+\frac{2}{\lambda_{X}^{5} \lambda_{Y}^{2}}+\frac{0.5}{\lambda_{X}^{4} \lambda_{Y}^{3}}\right), \\
H(x, y, Z)=2 \pi n_{0 Z}\left[0.78 \lambda_{\bar{Z}}^{2}+0.31 S_{c}^{1 / 3} \Gamma\right. \\
\left.\left(\frac{y+5}{2}\right) x^{1 / 2}\left(\frac{\rho_{0}}{\bar{\rho}}\right)^{1 / 4}{ }_{\nu-1 / 2} \lambda_{\bar{Z}}^{(y+5) / 2}\right], \\
I\left(Q_{V S I}\right)=\frac{1}{\bar{\rho}}\left[K_{a} T_{c}-L_{V} \psi \bar{\rho}\left(Q_{V S I}-Q_{V}\right)\right], \\
J\left(L_{V}, Q_{V S}\right)=\bar{\rho}\left(\frac{L_{V}^{2}}{K_{a} R_{w} T^{2}}+\frac{1}{\bar{\rho} Q_{V S} \psi}\right) .
\end{gathered}
$$

Here $\Gamma(x)$ is the gamma function with the argument $x, \bar{\rho}$ the density at the height $z, \rho_{0}$ the density at the surface, $S_{C}$ the Schmidt number, $\nu$ the kinetic viscosity of air, $K_{a}$ thermal conductivity of air, $\psi$ diffusivity of water vapor in air, $C_{i}$ specific heat of ice, $R_{w}$ specific gas constant for water vapor, $S_{i}$ saturation ratio over ice which is given by $Q_{V} / Q_{V S I}, S$ saturation ratio which is given by $Q_{V} / Q_{V S}$ and $T_{c}=$ $T-T_{0}\left(T_{0}=273.16 \mathrm{~K}\right) . Q_{V S}, Q_{V S I}$ and $Q_{V S I O}$ mean the saturation mixing ratios for water vapor with respect to water, with respect to ice and at surface of ice at $T=T_{0}$, respectively. $m_{I}$ is the weight of cloud ice and assumed to be $3.84 \times 10^{-12} \mathrm{~kg}$. The parameter $\mathrm{h}$ is given by $\left(\frac{4 g \rho_{H}}{3 C_{D} \rho_{0}}\right)^{1 / 2}$, where $C_{D}$ is the drage coeffi- cient for hail and given as 0.6. The growths of graupel and hail accretion are assumed to be two growth modes; wet and dry growth modes. $P_{G W E T}\left(P_{H W E T}\right)$ is the wet growth mode of graupel (hail) and given as

$$
\begin{aligned}
& P_{G W E T}=I\left(Q_{V S I O}\right) H(c, d ; G) /\left(L_{f}+C_{w} T_{c}\right) \\
& +P_{G A C I}^{\prime}\left(1-\frac{C_{i} T_{c}}{L_{f}+C_{w} T_{c}}\right) \\
& P_{H W E T}=I\left(Q_{V S I O}\right) H\left(h, \frac{1}{2} ; H\right) / \\
& \quad\left(L_{f}+C_{w} T_{c}\right)+P_{H A C I}^{\prime}\left(1-\frac{C_{i} T_{c}}{L_{f}+C_{w} T_{c}}\right) \\
& P_{G A C R}^{\prime} \text { and } P^{\prime}{ }_{H A C R} \text { are defined as } \\
& P_{G A C R}^{\prime}=P_{G W E T}-P_{G A C C}-P_{G A C I}^{\prime}
\end{aligned}
$$

and

$$
P_{H A C R}^{\prime}=P_{H W E T}-P_{H A C C}-P_{H A C I}^{\prime}-P_{H A C G}^{\prime} .
$$

On the other hand, $P_{G D R Y} \quad\left(P_{H D R Y}\right)$ is.the dry growth mode of graupel (hail) and given as

$$
P_{G D R Y}=P_{G A C C}+P_{G A C R}+P_{G A C I} \text {. }
$$

Similarly, $P_{G D R Y} \quad$ is given as

$$
P_{H D R Y}=P_{H A C C}+P_{H A C R}+P_{H A C I}+P_{H A C G} \text {. }
$$

When these two growth modes are compared, the smaller of the two is applied (Musil, 1970). For the wet growth mode, $P^{\prime}{ }_{G A C R}$ and $P^{\prime}{ }_{H A C R}$ are sometimes negative and shedding occurs in which transfer from accreted substances to rain takes place. The deposition term $P_{G D E P} \quad\left(P_{H D E P}\right)$ is the same form as the sublimation term $P_{G S U B}\left(P_{H S U B}\right)$, although its sign is opposite.

Fig. 17 shows production rates when (a) 
(a)

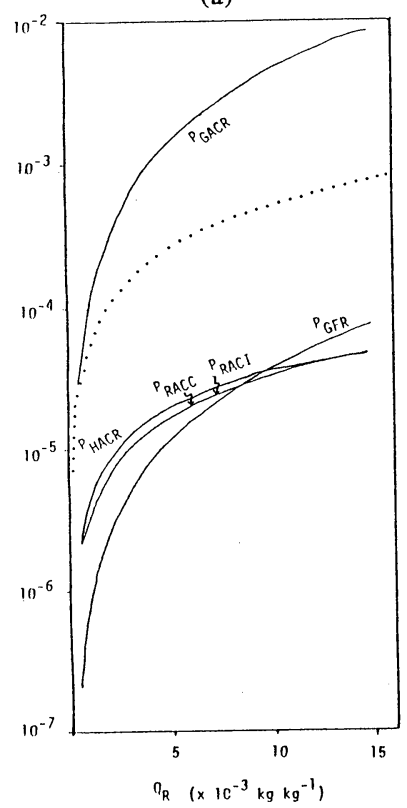

(b)

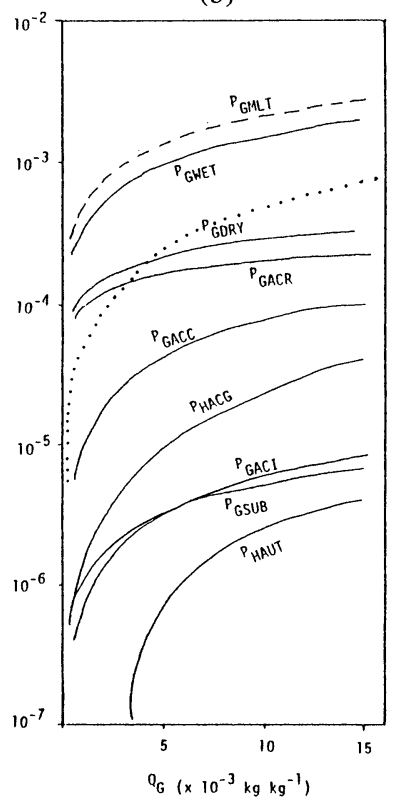

(c)

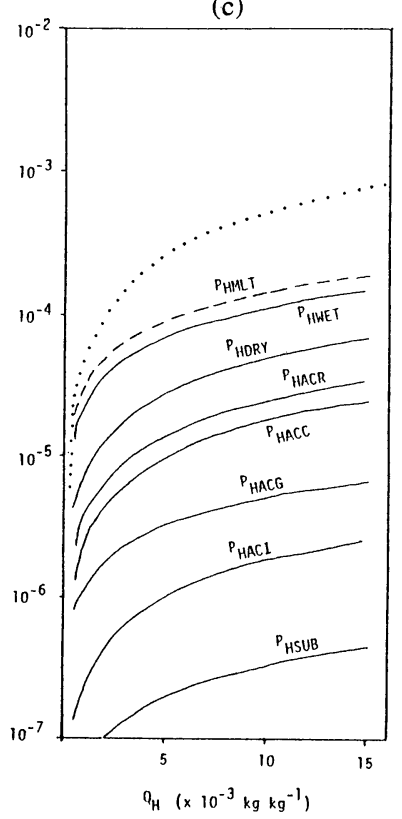

Fig. 17 Production rates. Variables in (a), (b) and (c) are $Q_{R}, Q_{G}$ and $Q_{H}$, respectively. When the production rate exceeds the critical value denoted by the dashed line, it is set to be the critical one.

$Q_{R}$, (b) $Q_{G}$ and (c) $Q_{H}$ are changed and the other variables are fixed. In order to prevent making negative values of the positive quantity $(Q)$, the maximum production rates are specified in the leap frog scheme as $P_{c}=\alpha Q^{(n-1)} / 2 \Delta t$, where $Q$ at $(n+1)$ time step is given as $Q^{(n+1)}=$ $Q^{(n-1)}-P^{(n)} 2 \Delta t$ and $\alpha$ is assumed to be 0.5 . When the production rate $P^{(n)}$ exceeds $P_{C}$ denoted by the dotted line, it is set to be $P_{C}$.

Exchanges among non-precipitating water substances enclosed by the dotted line in Fig. 3 occur instantaneously. $P_{C O N D}$ and $P_{C E V P}$ are similar to those given in Soong and Ogura (1973). $P_{I S U B}$ is the sublimation term to transfer from $Q_{I}$ to $Q_{V}$ when $Q_{V}<Q_{V S_{I}}$. $P_{I M L T}$ is the melting term which occurs for $T>T_{0}$. $P_{I H O M}$ and $P_{I H N}$ are homogeneous and heterogeneous nucleation terms. $P_{I H O M}$ takes place for $T<T_{1}=238.16 \mathrm{~K}\left(-35^{\circ} \mathrm{C}\right)$ to transfer all $Q_{C}$ to $Q_{I}$ isobarically. For $T_{1}<T<T_{0}, P_{I H N}$ occurs. It is assumed that $Q_{I}$ is denpendent on mixing ratio of active natural ice nuclei, $Q_{*}$, which is given by $Q_{*}=m_{I} N_{n}\left(T_{c}\right) / \vec{\rho}$. Here $N_{n}\left(T_{c}\right)$ is given by $n_{I} \exp \left(-a_{I} T_{c}\right)$, where $n_{I}=10^{-2}$ and $a_{I}=0.57$. If $Q_{I}$ is smaller than $Q_{*}$, cloud ice is produced until its mixing ratio reaches $Q_{*}$. On the other hand, if $Q_{I}$ is larger than $Q_{*}$, not transfer occurs.

\section{References}

Barker, E.J. and T.L. Baxter, 1975: A note on the computation of atmospheric surface fluxes for use in numerical modeling. J. Appl. Meteor., 14, 620622.

Barnes, G.M., E.J. Zipser, D. Jorgensen and F. Mark, Jr., 1983: Mesoscale and convective structure of a hurricane rainband. J. Atmos. Sci., 40, 2125-2137.

Brown, J.M., 1979: Mesoscale unsaturated downdraft driven by rainfall evaporation: A numerical study. J. Atmos. Sci., 36, 313-338.

Businger, J.A., J.C. Wyngaad, Y. Izumi and E.F. Bradley, 1971: Flux-profile relationships in the atmospheric surface layer. J. Atmos. Sci., 28, 181-189.

Federer, B. and A. Waldvogel, 1975: Hail and raindrop size distributions from a Swiss multicell storm. $J$. Appl. Meteor. 14, 91-97.

Gamache, J.F. and R.A. Houze, Jr., 1982: Mesoscale air motions associated with a tropical squall line. Mon. Wea. Rev., 110, 118-135.

Houze, R.A., Jr., 1977: Structure and dynamics of a tropical squall-line system. Mon. Wea. Rev., 105, 1540-1567. and K. Betts, 1981: Convection in GATE. 
Rev. Geophys. Space Phys., 19, 541-576.

Johnson, R.H. and M.E. Nicholls, 1983: A composite analysis of the boundary layer accompanying a tropical squall line. Mon. Wea. Rev., 111, 308-319.

Klemp, J.B. and R.B. Wilhelmson, 1978: The simulation of three-dimensional convective storm dynamics. J. Atmos. Sci., 35, 1070-1096.

Leary, C.A. and R.A. Houze, Jr., 1979a: The structure and evolution of convection in a tropical cluster. J. Atmos. Sci., 36, 437-457.

- 1979b: Melting and evaporation of hydrometeors in precipitation from the anvil clouds of deep tropical convection. J. Atmos. Sci., 36, 669679.

LeMone, M.A., 1983: Momentum transport by a line of cumulonimbus. J. Atmos. Sci., 40, 1815-1834.

, G.M. Barnes, E.J. Szoke and E.J. Zipser, 1984a: The tilt of the leading edge of mesoscale tropical convective lines. Mon. Wea. Rev., 112, 510-519.

- and E.J. Zipser, 1984b: Momentum flux by lines of cumulonimbus over the tropical oceans. J. Atmos. Sci., 41, 1914-1932.

Lin, Y.-L., R.D. Farley and R.D. Orville, 1983: Bulk parameterization of the snow filed in a cloud model. J. Climate Appl. Met., 22, 1065-1092.

Locatelli, J.D. and P.V. Hobbs, 1984: Fall speeds and masses of solid precipitation particles. J. Geophys. Res., 79, 2185-2197.

Mansfield, D.A., 1977: Squall lines observed in GATE. Quart. J. Roy. Met. Soc., 103, 569-574.

Marshall, J.S. and W.M. Palmer, 1948: The distribution of raindrops with size. J. Meteor., 5, 165-166.

Moncrieff, M.W. and M.J. Miller, 1976: The dynamics and simulation of tropical cumulonimbus and squall lines. Quart. J. Roy. Met. Soc., 102, $373-$ 394.

Musil, D.J., 1970: Computer modeling of hailstone growth in feeder clouds. J. Atmos. Sci., 27, 474482.

Nakamura, H., 1978: Dynamical effects of mountains on the general circulation of the atmosphere. I. $J$. Meteor. Soc. Japan, 56, 317-340.

Raymond, D.J., 1984: A wave-CISK model of squall lines. J. Atmos. Sci., 41, 1946-1958.

Roux, F., J. Testud, M. Payne and B. Pinty, 1984: West African squall-line thermodynamic structure retrieved from dual-Doppler radar observations. J. Atmos. Sci., 41, 3104-3121.

Soong, S.-T. and Y. Ogura, 1973: A comparison between axisymmetric and slab-symmetric cumulus cloud models. J. Atmos. Sci., 30, 879-893.

- and S.-C. Chen, 1984: The effect of wind shear and ice phase on the structure of a tropical cloud cluster. 15th Conf. on Hurricanes and Tropical Meteorology (A.M.S.), 181-182.

Yamasaki, M., 1984: Dynamics of convective clouds and 'CISK' in the vertical shear flow - with its application to easterly waves and squall-line systems. J. Meteor. Soc. Japan, 62, 833-863.

Yoshizaki, M., 1985: A new second-order finite-difference form of three-dimensional momentum equations in the anelastic system. J. Meteor. Soc. Japan, $63,397-404$.

\title{
熱帯スコールラインクラスターの数値実験： 2 次元
}

\author{
吉 崎 正 憲 \\ (東京大学海洋研究所) ${ }^{*}$
}

2 次元の非静水圧・非弾性系の雲モデルを用いて，1974年 9 月12日にGATE 領域で見られた熱帯スコ 一ルラインクラスター (TSL) の数值実験を行なった。水は, 水蒸気, 雲粒, 雨, 水雲粒, あられ, U

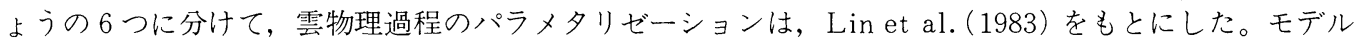
のグリッドは，水平・鉛直の両方向に可変で，領域は $241 \mathrm{~km} \times 14.45 \mathrm{~km}$ である。下層に収束のある大規 模場の中で，初期にサーマルを与えて対流雲を発生させた。

対流性と層状性の 2 つの領域の共存, 対流性領域での上昇流の傾き, 層状性領域での流れの層状構造 や雲の中の上昇流とその下の下降流，地表での風・温度・湿度・フラックスの急激なとびなどはよく再 現された。これらはTSLによく観測されるものである。しかしながら，TSLの1つの特徵である大 きな伝播速度は得られなかった。これは，シミュレートされた地上気圧のとびの強さが不十分であった ためと思われる。

*現在：イリノイ大学. 